\title{
Transmission-line-circuit model of an 85-TW, 25-MA pulsed-power accelerator
}

\author{
B. T. Hutsel, ${ }^{1,}{ }^{*}$ P. A. Corcoran, ${ }^{2}$ M. E. Cuneo, ${ }^{1}$ M. R. Gomez, ${ }^{1}$ M. H. Hess, ${ }^{1}$ D. D. Hinshelwood, ${ }^{3}$ \\ C. A. Jennings, ${ }^{1}$ G. R. Laity, ${ }^{1}$ D. C. Lamppa,${ }^{1}$ R. D. McBride, ${ }^{4}$ J. K. Moore,${ }^{1}$ A. Myers, ${ }^{2}$ \\ D. V. Rose, ${ }^{5}$ S. A. Slutz, ${ }^{1}$ W. A. Stygar, ${ }^{1}$ E. M. Waisman, ${ }^{1}$ D. R. Welch, ${ }^{5}$ and B. A. Whitney ${ }^{2}$ \\ ${ }^{1}$ Sandia National Laboratories, Albuquerque, New Mexico 87185, USA \\ ${ }^{2}$ L-3 Applied Technologies, San Leandro, California 94577, USA \\ ${ }^{3}$ Naval Research Laboratory, Washington, DC 20375, USA \\ ${ }^{4}$ University of Michigan, Ann Arbor, Michigan 48109, USA \\ ${ }^{5}$ Voss Scientific, Albuquerque, New Mexico 87108, USA
}

(Received 10 October 2017; published 23 March 2018)

\begin{abstract}
We have developed a physics-based transmission-line-circuit model of the $\mathrm{Z}$ pulsed-power accelerator. The 33-m-diameter $Z$ machine generates a peak electrical power as high as $85 \mathrm{TW}$, and delivers as much as $25 \mathrm{MA}$ to a physics load. The circuit model is used to design and analyze experiments conducted on $Z$. The model consists of 36 networks of transmission-line-circuit elements and resistors that represent each of Zs 36 modules. The model of each module includes a Marx generator, intermediate-energy-storage capacitor, laser-triggered gas switch, pulse-forming line, self-break water switches, and tri-plate transmission lines. The circuit model also includes elements that represent Zs water convolute, vacuum insulator stack, four parallel outer magnetically insulated vacuum transmission lines (MITLs), double-post-hole vacuum convolute, inner vacuum MITL, and physics load. Within the vacuum-transmission-line system the model conducts analytic calculations of current loss. To calculate the loss, the model simulates the following processes: (i) electron emission from MITL cathode surfaces wherever an electric-field threshold has been exceeded; (ii) electron loss in the MITLs before magnetic insulation has been established; (iii) flow of electrons emitted by the outer-MITL cathodes after insulation has been established; (iv) closure of MITL anode-cathode (AK) gaps due to expansion of cathode plasma; (v) energy loss to MITL conductors operated at high lineal current densities; (vi) heating of MITL-anode surfaces due to conduction current and deposition of electron kinetic energy; (vii) negative-space-charge-enhanced ion emission from MITL anode surfaces wherever an anode-surface-temperature threshold has been exceeded; and (viii) closure of MITL AK gaps due to expansion of anode plasma. The circuit model is expected to be most accurate when the fractional current loss is small. We have performed circuit simulations of $52 \mathrm{Z}$ experiments conducted with a variety of accelerator configurations and load-impedance time histories. For these experiments, the apparent fractional current loss varies from $0 \%$ to $20 \%$. Results of the circuit simulations agree with data acquired on 52 shots to within $2 \%$.
\end{abstract}

DOI: 10.1103/PhysRevAccelBeams.21.030401

\section{INTRODUCTION}

The $\mathrm{Z}$ pulsed-power accelerator at Sandia National Laboratories is a 33-m-diameter, 36-module pulsed-power accelerator. At a Marx-capacitor-charge voltage of $85 \mathrm{kV}$, $\mathrm{Z}$ stores $20 \mathrm{MJ}$ of electrical energy, generates peak electrical powers as high as $85 \mathrm{TW}$, and delivers as much as 25 MA to a physics load $[1,2]$.

\footnotetext{
*bthutse@sandia.gov
}

Published by the American Physical Society under the terms of the Creative Commons Attribution 4.0 International license. Further distribution of this work must maintain attribution to the author(s) and the published article's title, journal citation, and DOI.
The $\mathrm{Z}$ accelerator supports a variety of high-energydensity (HED) physics experiments in the fields of inertial confinement fusion (ICF) [3-5], radiation-effects science (RES) [6,7], material physics [8,9], radiation physics [10], laboratory astrophysics [11], accelerator physics, and other research areas. The physics loads used in these experiments have a variety of impedance time histories with loadcurrent pulse lengths that range from $100 \mathrm{~ns}$ to $2 \mu \mathrm{s}$.

We have developed a transmission-line-circuit model of the $\mathrm{Z}$ accelerator using the Bertha circuit code [12] to facilitate the design and analysis of experiments conducted on $\mathrm{Z}$. The $\mathrm{Z}$ circuit model is used in both a predictive mode and to perform post-shot analysis. In a predictive mode, the model has been used to estimate the 
energy delivered to a load and to determine the accelerator configuration necessary to generate a desired pulse shape. In post-shot analysis, the model has been used to provide a measure of the delivered load current and to help diagnose accelerator issues.

The model includes networks of transmission lines and resistors that represent each of the 36 energy-storage and pulse-forming modules, the water convolute, vacuum insulator stack, four parallel outer magnetically insulated transmission lines (MITLs), double-post-hole vacuum convolute (DPHC or vacuum convolute), inner MITL, and physics load. The model is an extension of previous circuit models of $\mathrm{Z}$ which included only Z's system of vacuum transmission lines [13] or used a single equivalent representation of the 36 energy storage and pulse-forming modules [14].

This paper details the recent development of the circuit model based on comparing simulation results to $52 \mathrm{Z}$ shots. Two substantial changes include: (i) refinement of model parameters used for the laser-triggered gas switch (LTGS) and self-breaking water switches within the pulse-forming modules and (ii) new analytic calculations of current loss that occurs within the high-energy-density regions of the vacuum transmission line system. A particle swarm optimization technique [15] was used to determine model parameter values that best fit experiment data for both of these changes.

The paper is organized as follows: in Sec. II we describe the topology of the circuit model. In Sec. III we describe the current-loss mechanisms implemented within the vacuum regions of the accelerator. In Sec. IV we describe the optimization of current-loss model parameters and an error analysis of the model. In Sec. V we compare post-shot simulations with $\mathrm{Z}$ data measured on a variety of experiments including short-circuit [16], MagLIF [5], linerdynamics [17-19], nested tungsten wire arrays [20], nested stainless-steel wire arrays [21], and dynamic-holhraum
[11]. Section VI presents conclusions and future work. Three appendices provide additional details on calculations used in the circuit model.

\section{CIRCUIT MODEL TOPOLOGY}

The transmission-line-circuit model of $\mathrm{Z}$ represents the entire accelerator, from the capacitive energy storage of the Marx generators to the load. A cross-sectional view of the $\mathrm{Z}$ accelerator is shown in Fig. 1. Descriptions of the Z's architecture are given in Refs. [2,22]. A corresponding block diagram of the transmission-line-circuit model representation of $\mathrm{Z}$ is shown in Fig. 2.

\section{A. Pulseline modules}

The 36 energy-storage and pulse-forming modules are arranged in pairs, as shown in Fig. 1. Each module includes a Marx generator, intermediate-energy-storage capacitor (IS), laser-triggered gas switch (LTGS), coaxial pulseforming line (PFL), self-breaking water switches (main and pre-pulse), and tri-plate transmission lines (OTL1 and OTL2). The circuit models of each of these components are described in Ref. [14].

A significant update to the pulseline circuit elements, compared to Ref. [14], was the refinement of the resistance and inductance used in the models of the LTGS and the self-breaking water switches. The resistance and inductance of these switches were optimized using data from $11 \mathrm{Z}$ shots that used a low-inductance, short-circuit load. This configuration avoids the complications and uncertainty of modeling time-varying loads and current loss in the vacuum region of the $\mathrm{Z}$ accelerator that are present with more complicated loads. These 11 shots were conducted with a variety of Marx charge voltages and self-breaking water-switch configurations. Table I summarizes the machine configurations used with the short-circuit load.

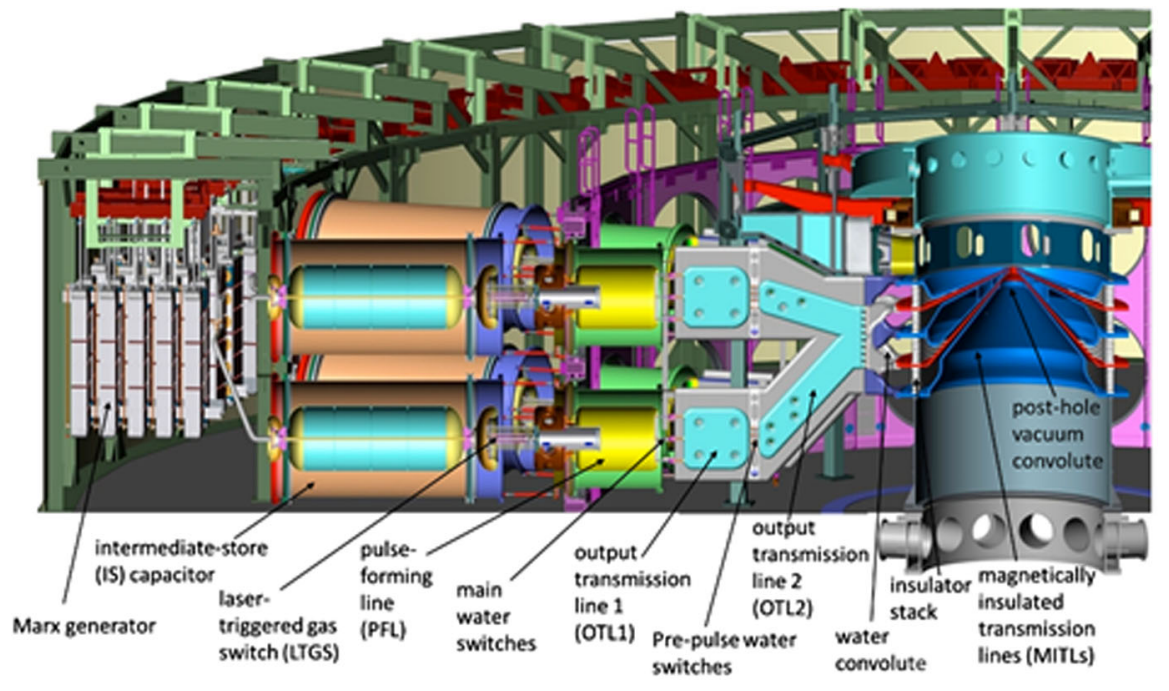

FIG. 1. Cross-sectional view indicating the major components of the $\mathrm{Z}$ accelerator. 


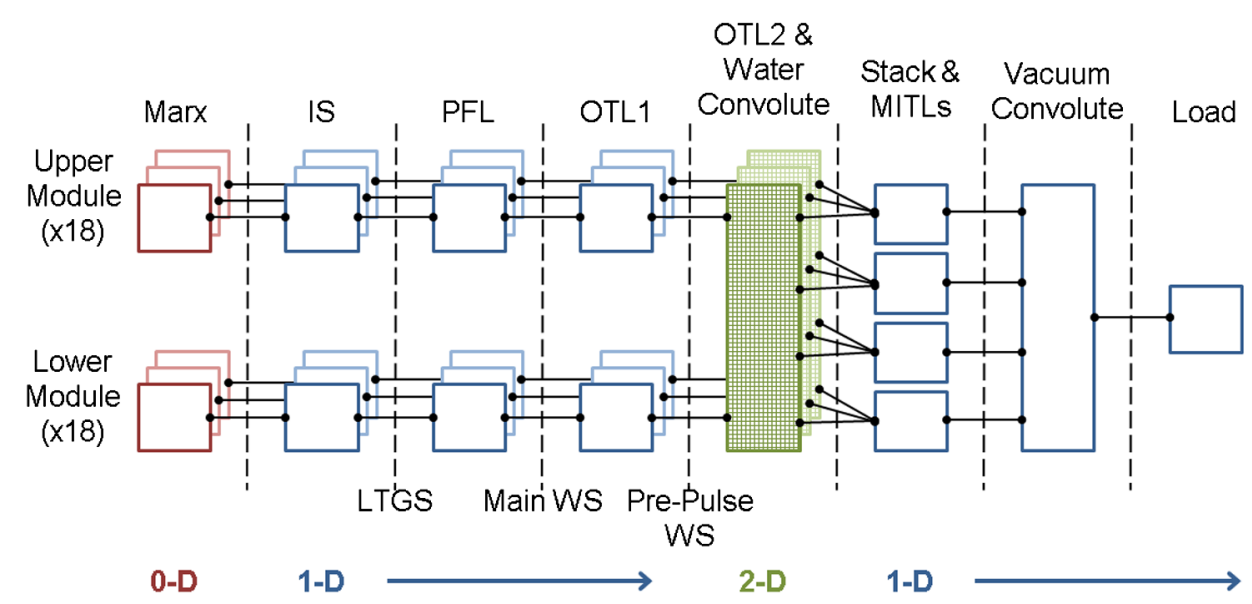

FIG. 2. Block diagram of the tranmisison-line-circuit model representation of the $\mathrm{Z}$ accelerator.

Typical values for the switch resistance and inductance for a shot with an $85 \mathrm{kV}$ Marx charge voltage are shown in Table II.

We assume a constant inductance and a time-varying resistance that monotonically decreases with time for the models of the LTGS and self-breaking water switches. The functional form of the resistance is expressed as,

$$
R(t)=R_{i}+\frac{R_{f}-R_{i}}{2}\left[1-\tanh \left(\frac{t-t_{\mathrm{sw}}}{\tau_{\mathrm{sw}}}\right)\right]
$$

TABLE I. Machine configurations of the short-circuit shots used to refine the resistance and inductance of the laser-triggered gas switch and self-breaking water switch models. A switch gap of $0 \mathrm{~cm}$ represents an electrode gap that is electrically shorted.

\begin{tabular}{lccc}
\hline \hline Shots & $\begin{array}{c}\text { Marx charge } \\
\text { voltage }\end{array}$ & $\begin{array}{c}\text { Main } \\
\text { WS gap }\end{array}$ & $\begin{array}{c}\text { Pre-pulse } \\
\text { WS gap }\end{array}$ \\
\hline 2225,2546 & $70 \mathrm{kV}$ & $0 \mathrm{~cm}$ & $0 \mathrm{~cm}$ \\
2266,2499 & $70 \mathrm{kV}$ & $3.5 \mathrm{~cm}$ & $0 \mathrm{~cm}$ \\
2280,2313 & $70 \mathrm{kV}$ & $10 \mathrm{~cm}$ & $0 \mathrm{~cm}$ \\
2458,2569 & $70 \mathrm{kV}$ & $10 \mathrm{~cm}$ & $3 \mathrm{~cm}$ \\
2649 & $50 \mathrm{kV}$ & $0 \mathrm{~cm}$ & $0 \mathrm{~cm}$ \\
2598 & $50 \mathrm{kV}$ & $6 \mathrm{~cm}$ & $0 \mathrm{~cm}$ \\
2663 & $50 \mathrm{kV}$ & $6 \mathrm{~cm}$ & $2 \mathrm{~cm}$ \\
\hline \hline
\end{tabular}

TABLE II. Typical switch parameter values for a shot configured with an $85 \mathrm{kV}$ Marx charge voltage. The inductance values represent the arc inductance (i.e., the increase in inductance over a shorted switch). The LTGS resistance and inductance have a small dependence on switch voltage. The water switch inductance and resistance vary with the electrode gap spacing.

\begin{tabular}{lcrr}
\hline \hline Switch & $R_{f}$ & $\tau_{\mathrm{sw}}$ & Inductance \\
\hline LTGS & 0.487 & $22.5 \mathrm{~ns}$ & $120 \mathrm{nH}$ \\
main WS & 0.273 & $6.9 \mathrm{~ns}$ & $60.7 \mathrm{nH}$ \\
pre-pulse WS & 0.230 & $2.6 \mathrm{~ns}$ & $9 \mathrm{nH}$ \\
\hline \hline
\end{tabular}

where, $R_{i}$ is the initial resistance, $R_{f}$ is the final resistance, $t_{\mathrm{sw}}$ is the switching time, and $\tau_{\mathrm{sw}}$ is the time constant of the resistive fall. The exact functional form of the resistance is not critical as the model only needs to capture the general switching behavior of the 36 lines.

\section{B. Vacuum section}

The transmission-line representation of the vacuum section can be divided into three regions; the outer MITLs, the double-post-hole vacuum convolute, and the inner MITL. The outer MITLs consist of four parallel transmission lines which extend from the vacuum insulator stack to a radius of approximately $10 \mathrm{~cm}$. The vacuum convolute, which extends from a radius of $10 \mathrm{~cm}$ to $6 \mathrm{~cm}$, combines the four parallel outer MITLs into a single inner MITL. The inner MITL delivers energy from a radius of $6 \mathrm{~cm}$ to the load. Within these regions the model performs analytic calculations of current loss. A description of the current-loss model is given in Sec. III.

The load is modeled as a single circuit element with a time-varying inductance. Depending on the experiment, the load inductance is either prescribed as a function of time or varies self-consistently assuming a snowplow implosion model or a wire-ablation model [23].

\section{VACUUM SECTION CURRENT-LOSS DESCRIPTION}

The circuit-model representation of the vacuum section of the accelerator consists of transmission-line-circuit elements, series resistors, and shunt resistors. Both the series and shunt resistances are adjusted by subroutines to simulate energy losses in the transmission-line elements. The subroutines account for the following processes: (i) electron emission from MITL-cathode surfaces wherever an electric-field threshold has been exceeded; (ii) electron loss in the MITLs before magnetic insulation has been established; (iii) MITL-electron-flow current after insulation has been achieved; (iv) closure of MITL anode-cathode (AK) gaps 
due to expansion of cathode plasma; (v) energy loss to MITL conductors operated at high lineal current densities; (vi) heating of MITL-anode surfaces due to conduction current and deposition of electron kinetic energy; (vii) negative-space-charge-enhanced ion emission from MITL-anode surfaces wherever a surface-temperature threshold has been exceeded; and (viii) closure of MITL AK gaps due to expansion of anode plasma.

Loss mechanisms are enabled or disabled in each element depending on the elements location. Loss mechanisms (i)-(iv) are evaluated in the outer MITLs. The current densities within the outer MITLs are low enough that we neglect loss mechanisms (v)-(viii). Within the vacuum convolute and inner MITL all loss mechanisms except for (iii) are evaluated. The strong magnetic insulation in the convolute and inner MITL results in negligible electron flow current.

\section{A. Electron emission from cathode surfaces}

Within the outer MITLs, vacuum convolute, and inner MITL we assume electrons are emitted from the cathode of any circuit element at which the electric field has previously exceeded a threshold [24]

$$
E_{\text {thresh }}=2.4 e 7 \mathrm{~V} / \mathrm{m} \text {. }
$$

\section{B. Electron loss prior to magnetic insulation}

Prior to magnetic insulation, electrons emitted from the cathode are assumed to be lost locally to the anode. The lost electron current is given by the space-charge-limited current with a correction for the magnetic field [25]. The correction monotonically decreases the loss current from the space-charge-limited current to zero as the magnetic field approaches and exceeds the cutoff magnetic field, similar to the corrections described in Refs. [26,27]. In the circuit model of the $\mathrm{Z}$ accelerator, the results are not sensitive to the exact form of the correction because the MITLs become magnetically insulated early in the pulse, and the electron losses prior to magnetic insulation are negligible.

\section{Electron flow current after magnetic insulation}

Once magnetic insulation has been established, the flow current in each element is calculated as the average of the collisionless and collisional flow limits as given by [28],

$$
I_{f}=\frac{13}{16} \frac{V^{2}}{I_{a} Z^{2}},
$$

where $V$ is the voltage at the element, $I_{a}$ is the element's anode current, and $Z$ is the vacuum impedance of the element. As noted in Ref. [28], Eq. (3) is valid only when the MITLs are strongly insulated. As with the electron loss prior to magnetic insulation described in Sec. III B, the model results are not sensitive to this assumption because the outer MITLs become magnetically insulated early in the current pulse and operate in the well-insulated limit for the majority of the current pulse.

The electron flow current that originates in the outer MITLs is assumed to propagate through the outer MITLs in the direction of power flow and into the vacuum convolute and inner MITL regions. Details on the calculation of the flow current in the outer MITL transmission line elements are included in Appendix A. Details regarding how the model distributes the outer MITL flow current entering the vacuum convolute and inner MITL regions are included in Appendix B.

\section{MITL gap closure due to cathode plasma expansion}

Cathode plasma expansion is enabled in circuit elements where the electric field has previously exceeded $E_{\text {thresh }}$. We assume the measured cathode plasma expansion velocity given by Ref. [29]

$$
v_{c}=1.1 e 4 \mathrm{~m} / \mathrm{s} .
$$

\section{E. Energy lost to conductors at high lineal current densities}

Within the high-current-density regions of the vacuum convolute and inner MITL we model energy lost to the conductors due to ohmic heating, magnetic diffusion, and conductor motion as described in Ref. [30].

\section{F. Ion emission from anode conductors}

Within the high-current-density regions of the vacuum convolute and inner MITL we model ion emission from anode surfaces that are sufficiently heated. Ion emission is enabled in circuit elements where the anode surface temperature increases by a threshold [31,32],

$$
\Delta T_{\text {thresh }}=400 \mathrm{~K} \text {. }
$$

In the absence of negative space charge within the AK gap of a vacuum transmission line, the space-chargelimited (SCL) ion current is given by,

$$
I_{\mathrm{SCL}}=\frac{4 \varepsilon_{0}}{9} A \sqrt{\frac{2 q}{m}} \frac{V^{3 / 2}}{d^{2}},
$$

where $\varepsilon_{0}$ is the permittivity of free space, $A$ is the area of the element, $q$ is the ion species charge, $m$ is the ion species mass, $V$ is the electric potential of the accelerating gap, and $d$ is the distance from the anode to the cathode.

We assume the ion loss current is enhanced by the presence of negative space charge from electron flow 
current that enters the vacuum convolute and inner MITL regions from the upstream outer MITLs [33]. The enhanced space charge limited current is given by

$$
I_{\text {ion }}=\eta I_{\mathrm{SCL}} \text {. }
$$

The enhancement factor, $\eta$, is estimated as follows:

$$
\eta=\frac{3}{4} k_{\mathrm{vi}} Q_{e} \frac{d}{\varepsilon_{0} A V},
$$

where $k_{\mathrm{vi}}$ is a constant representing the average ion velocity within the gap, and $Q_{e}$ is the accumulated electron charge. If $\eta$ is less than one, the enhancement is set equal to one. The derivation of equation (8) and a discussion on the ion loss current enhancement is included in Appendix C.

The effective ion species mass-to-charge ratio in Eq. (6) is adjusted to account for magnetic insulation of the ions. The mass-to-charge ratio is adjusted based on the Hull cutoff criterion [34]. The minimum, noninsulated, effective mass-to-charge ratio is assumed to be as follows:

$$
\frac{m}{q}=\frac{1}{2 V}\left(\frac{\mu_{0} I d}{2 \pi r}\right)^{2} .
$$

Initially, the ion species is assumed to be protons. If protons are magnetically insulated, the next ion species is assumed to be sourced from water contaminants on the power-flow surfaces and assumed to be oxygen $2+$. For larger mass-to-charge ratios, the ratio is continually adjusted to the threshold value of mass-to-charge given by Eq. (9).

The anode temperature rise was estimated from ohmic heating and electron-energy deposition to the anode from the lost electron flow current,

$$
\Delta T=\frac{\vartheta B^{2}}{2 \mu_{0} c_{v}}+\int_{0}^{t} \frac{V I_{\mathrm{fl}}}{m_{a} c_{v}} d t .
$$

The quantity $V$ is the element voltage, $I_{\mathrm{fl}}$ is the flow current from the outer MITLs that is lost within that element, $m_{a}$ is the anode electrode mass to which the electrons deposit energy, and $c_{v}$ is the specific heat per unit volume of the conductor. The first term on the right side of Eq. (10) accounts for ohmic heating of the conductor as given by [30]. The second term accounts for energy deposited by the electron flow current that originates in the outer MITLs and is assummed to be lost to the anode within the vacuum convolute and inner MITL. The anode electrode mass is a function of time and is given by

$$
m_{a}=A \frac{\mathrm{eV}}{S_{P}} \sin \theta .
$$

where $S_{P}$ is the total stopping power of an electron given by Ref. [35], and $\theta$ is the angle of incidence, relative to the electrode surface, for the electrons. When determining the stopping power, the kinetic energy of the electron impacting the anode is assumed to be equal to the potential energy given by the element voltage, $\mathrm{eV}$.

\section{G. Anode-plasma expansion}

Anode-plasma expansion is enabled in the vacuum convolute and inner MITL circuit elements where the temperature threshold, $\Delta T_{\text {thresh }}$, has been exceeded. We assume the effective anode-plasma expansion velocities in the vacuum convolute, $v_{a, \mathrm{vc}}$, and inner MITL, $v_{a, \mathrm{im}}$, are as follows:

$$
\begin{aligned}
& v_{a, \mathrm{vc}}=17 e 4 \mathrm{~m} / \mathrm{s} \\
& v_{a, \mathrm{im}}=3.7 e 4 \mathrm{~m} / \mathrm{s} .
\end{aligned}
$$

Within the vacuum convolute and inner MITL, both the anode- and cathode-plasma expansion velocities reduce the effective element AK gap. The effective AK gap is given by

$$
d=d_{0}-v_{c}\left(t-t_{c}\right)-v_{a}\left(t-t_{a}\right)
$$

where $d_{0}$ is the initial AK gap, $t$ is the simulation time, $t_{c}$ is the time at which the cathode-plasma expansion begins,

TABLE III. Current-loss-model parameter values obtained from the loss model swarm optimization.

\begin{tabular}{llccc}
\hline \hline Parameter & \multicolumn{1}{c}{ Description } & Value & Min & Max \\
\hline$e_{f, \mathrm{vc}}$ & Fraction of outer MITL flow current into the DPHC & 0.888 & 0.750 & 0.942 \\
$e_{\mathrm{en}, \mathrm{vc}}$ & Fraction of flow current into the DPHC that enhances ion current & 0.045 & 0.024 & 0.051 \\
$e_{\mathrm{en}, \mathrm{im}}$ & Fraction of flow current into the inner MITL that enhances ion current & 0.179 & 0.064 & 0.197 \\
$\theta$ & Angle of incidence of flow electrons impacting anode surface (degrees) & 8 & 6 & 10 \\
$v_{a, \mathrm{vc}}$ & Anode plasma expansion velocity in the vacuum convolute $(\mathrm{m} / \mathrm{s})$ & $17.0 \mathrm{e} 4$ & $15.5 \mathrm{e} 4$ & $19.8 \mathrm{e} 4$ \\
$v_{a, \mathrm{im}}$ & Anode plasma expansion velocity in the inner MITL (m/s) & $3.7 \mathrm{e} 4$ & $1.1 \mathrm{e} 4$ & $3.9 \mathrm{e} 4$ \\
$k_{\mathrm{vi}}$ & Average ion velocity constant & 1.3 & 1.0 & 1.3 \\
$d_{\min }$ & minimum AK gap permitted in the DPHC and inner MITL (mm) & 2.0 & 1.7 & 2.5 \\
$k_{\mathrm{rt}}$ & outer MITL electron flow retrapping fraction & 0.074 & 0.041 & 0.087 \\
\hline \hline
\end{tabular}


and $t_{a}$ is the time at which the anode-plasma expansion begins. The large total plasma closure velocity in the convolute is in rough agreement with the vacuum convolute plasma measurements reported in Ref. [36].

\section{MODEL OPTIMIZATION AND ERROR ANALYSIS}

The current-loss model described in Sec. III contains several input parameters that were not constrained based on published data and are likely geometry dependent. These parameters are described in Table III. These parameter values were empirically determined using a using a particle swarm optimization [15] which varied each parameter value (within a reasonable range) until the simulation results best matched experiment data. The optimization used data from six $\mathrm{Z}$ shots with different load-impedance time histories and sought to minimize the difference between the simulated and measured insulator-stack currents and load-implosion times.

To determine the parameter values, the particle-swam optimization was run 20 times. Each optimization was initialized with random parameter values. The parameter values that were selected to use with the model were taken from the optimization run with the best overall fit to the measured data. Results from the other optimization runs were used to determine parameter sensitivity and estimate the random error in the optimization. The parameter values that were selected to use with the model, along with the maximum and minimum values from all 20 optimization runs, are listed in Table III.

The random and systematic errors in the optimization process were evaluated using multiple optimization runs. The random error in the optimization was determined using the results of the 20 independent optimization runs. The simulated load currents from all 20 independent optimizations varied less than $2 \%(2 \sigma)$ at peak current. At the time of stagnation, where the current varies rapidly for the largediameter wire arrays, the simulated load current varied up to $8 \%(2 \sigma)$. Figure 3 shows the average simulated load current with $2 \sigma$ error bars and the percent deviation for three shots.

Systematic error in the circuit-model optimization may be caused by errors in the measured data that the simulations were optimized against. The systematic error was estimated by completing additional optimizations with systematic adjustments to the measured stack-current and implosion times that the model was optimized towards. The stack current amplitudes were adjusted by $+/-2 \%$ and the measured implosion times were adjusted by $+/-2 \mathrm{~ns}$. The resulting systematic error in the simulated load currents for each of these cases was less than $8 \%(2 \sigma)$ through peak current. At the time of stagnation, where the current varies rapidly for the large-diameter wire arrays, the systematic error in the load current was as high as $14 \%(2 \sigma)$.
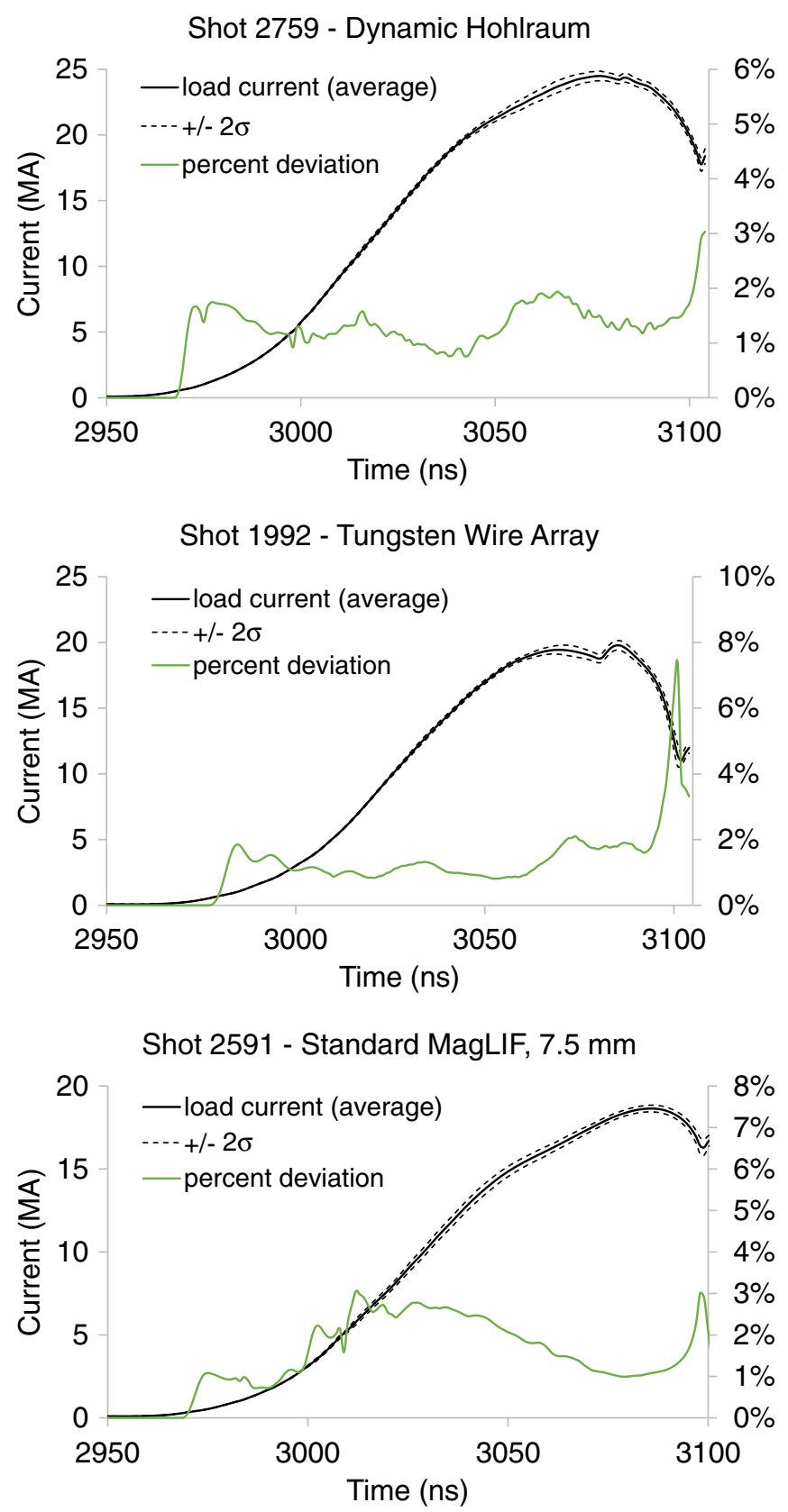

FIG. 3. Representation of the random error in the load current due to the swarm optimization process. Each figure shows the average load current with $+/-2 \sigma$ bounds and the percent deviation $(2 \sigma)$ using the results from 20 swarm optimization runs.

\section{Z SHOT COMPARISONS}

The circuit model was benchmarked against a total of 52 $\mathrm{Z}$ shots. Every simulation presented in this section was run using the parameter values listed in Table III. The selected shot types included short-circuit [16], MagLIF [5], linerdynamics [17-19], nested tungsten wire arrays [20], nested stainless-steel wire arrays [21], and dynamic-holhraum [11]. These shots cover a range of measured current loss due to their variety of load-impedance time histories and 
TABLE IV. Summary of $\mathrm{Z}$ shot configurations used to benchmark the circuit model. The physics-load implosion times range from $100 \mathrm{~ns}$ to $130 \mathrm{~ns}$; hence the simulated implosion times agree with the measured values to within $2 \%$.

\begin{tabular}{|c|c|c|c|c|c|c|c|}
\hline Experiment type & $\begin{array}{l}\text { No. of } \\
\text { shots }\end{array}$ & $\begin{array}{c}\text { Marx } \\
\text { charge } \\
\text { voltage }\end{array}$ & $\begin{array}{l}\text { Minimum inner } \\
\text { MITL A-K gap }\end{array}$ & $\begin{array}{c}\text { Initial } \\
\text { inductance } \\
(r<5.5 \mathrm{~cm})\end{array}$ & $\begin{array}{l}\text { Maximum pointwise } \\
\text { standard deviation } \\
\text { of stack current }\end{array}$ & $\begin{array}{c}\text { Maximum } \\
\text { deviation of } \\
\text { stagnation time }\end{array}$ & $\begin{array}{c}\text { Average peak } \\
\text { load current }\end{array}$ \\
\hline MagLIF (10 mm liner) & 7 & $80 \mathrm{kV}$ & $3 \mathrm{~mm}$ & $6.9 \mathrm{nH}$ & $1.9 \%$ & $1.9 \mathrm{~ns}$ & 17.6 MA \\
\hline MagLIF (7.5 mm liner) & 6 & $80 \mathrm{kV}$ & $3 \mathrm{~mm}$ & $6.1 \mathrm{nH}$ & $1.6 \%$ & $1.5 \mathrm{~ns}$ & 18.6 MA \\
\hline MagLIF (low inductance) & 1 & $80 \mathrm{kV}$ & $4 \mathrm{~mm}$ & $4.0 \mathrm{nH}$ & $1.1 \%$ & $0.5 \mathrm{~ns}$ & $19.7 \mathrm{MA}$ \\
\hline Liner dynamics & 3 & $80 \mathrm{kV}$ & $4 \mathrm{~mm}$ & $4.7-5.3 \mathrm{nH}$ & $1.0 \%$ & $\mathrm{n} / \mathrm{a}$ & $21.5 \mathrm{MA}$ \\
\hline Tungsten wire array & 8 & $80 \mathrm{kV}$ & $7 \mathrm{~mm}$ & $2.7 \mathrm{nH}$ & $1.9 \%$ & $1.8 \mathrm{~ns}$ & 19.8 MA \\
\hline Stainless-steel wire array & 6 & $80 \mathrm{kV}$ & $7 \mathrm{~mm}$ & $2.7-\mathrm{nH}$ & $1.6 \%$ & $1.4 \mathrm{~ns}$ & 19.1 MA \\
\hline Dynamic hohlraum & 4 & $85 \mathrm{kV}$ & $6 \mathrm{~mm}$ & $2.8-\mathrm{nH}$ & $1.3 \%$ & $1.2 \mathrm{~ns}$ & $24.7 \mathrm{MA}$ \\
\hline Short-circuit & 17 & $50,70 \mathrm{kV}$ & $6 \mathrm{~mm}$ & $1.8-\mathrm{nH}$ & $1.5 \%$ & $\mathrm{n} / \mathrm{a}$ & $\mathrm{n} / \mathrm{a}$ \\
\hline
\end{tabular}

inner MITL designs. A summary of all the shot types and the simulation results are shown in Table IV.

\section{A. Short-circuit}

The short-circuit load consists of a $2.0 \mathrm{~cm}$ radius post that terminates a radial inner MITL. This low-inductance load results in negligible current losses in the vacuum convolute and inner MITL. The short-circuit shots were used to benchmark the transmission-line-circuit model of $\mathrm{Z}$ in the absence of current loss.

Post-shot simulations were done on seventeen shortcircuit shots that spanned pulse lengths of $100 \mathrm{~ns}$ to $700 \mathrm{~ns}$. Comparisons of the insulator-stack-current time history for six shots are shown in Fig. 4. The insulator-stack current was compared using a normalized pointwise standard deviation. The simulated- and measured-stack currents agreed to within $1.5 \%$ for all of the simulated short-circuit shots.

\section{B. MagLIF}

The MagLIF load consists of a cylindrical beryllium liner. The standard MagLIF liner has an outer radius of $2.79 \mathrm{~mm}$ and an inner radius of $2.33 \mathrm{~mm}$. The imploding length of the liner is typically $7.5 \mathrm{~mm}$ or $10 \mathrm{~mm}$. Simulations of the MagLIF experiments used a snowplow-implosion model to simulate the imploding liner. The snowplow-implosion model assumes a 1D, perfectly stable implosion of the liner where all the current initially flows at the outer radius of the liner. The imploding mass accumulates until the simulated radius reaches the inner radius of the liner. Once the simulated radius reaches the inner radius of the liner, the entire liner mass continues to implode. The simulated-liner implosion time was assumed to be the time when the simulated radius reaches $0.4 \mathrm{~mm}$ (i.e., at a $7: 1$ convergence ratio). The $7: 1$ convergence ratio for the snowplow-implosion model was chosen based on comparisons to a semianalytic model of the MagLIF implosions [37]. The experimental implosion time was given by the peak of the x-ray emission from the target measured with photo conducting detectors (PCDs) [19].
Post-shot simulations were done on seven MagLIF shots with a $10 \mathrm{~mm}$ tall target, six MagLIF shots with a $7.5 \mathrm{~mm}$ tall target, and one additional MagLIF shot with a lowinductance inner MITL. Comparisons of the insulator-stack time history and the load implosion time are shown in Fig. 5 for two shots with a $10 \mathrm{~mm}$ target, Fig. 6 for two shots with a $7.5 \mathrm{~mm}$ target, and Fig. 7 for a MagLIF shot with a low-inductance inner MITL. The insulator-stack current was compared using a normalized pointwise standard deviation. The overall shape of the simulated and measured stack current agrees to within $2 \%$ for all of the simulated MagLIF shots. The simulated and measured liner implosion time agreed to within $2 \mathrm{~ns}$ for all of the simulated MagLIF shots.

\section{Liner dynamics}

The liner-dynamics experiments used either a beryllium or an aluminum cylindrical liner load with an outer radius of $3.47 \mathrm{~mm}$. The inner radius of the beryllium liner was $2.89 \mathrm{~mm}$. The inner radius of the aluminum liner was larger, $3.08 \mathrm{~mm}$, to keep the total liner mass the same. The liner-dynamics simulations used the same snowplowimplosion model described for the MagLIF shots. The liner-dynamics experiments utilized radiography to image the imploding load at two points in time. The simulated liner radius was compared to the measured liner radius from the radiographs.

Three post-shot simulations of liner-dynamics experiments were conducted. Comparisions between the measured and simulated stack current and liner radius for one shot are shown in Fig. 8. The overall shape of the simulated and measured stack current agrees to within $1.5 \%$ for all three simulated liner-dynamics shots. The simulated liner radius was in good agreement with observed liner radius from the radiographs in all three shots.

\section{Nested tungsten wire arrays}

The tungsten wire-array load consists of two components: a $3.25 \mathrm{~cm}$ initial radius, $1.66 \mathrm{mg}$ outer wire array and a $1.63 \mathrm{~cm}$ initial radius, $0.83 \mathrm{mg}$ inner array. The axial 


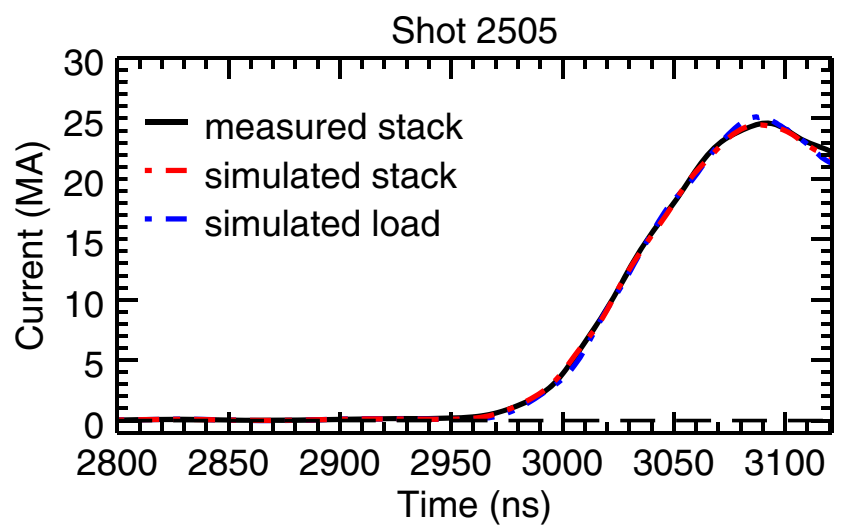

(a)

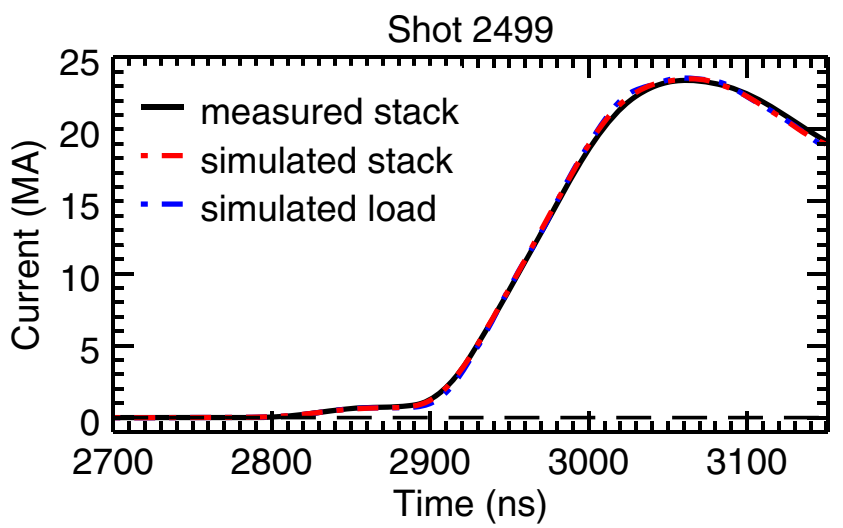

(c)

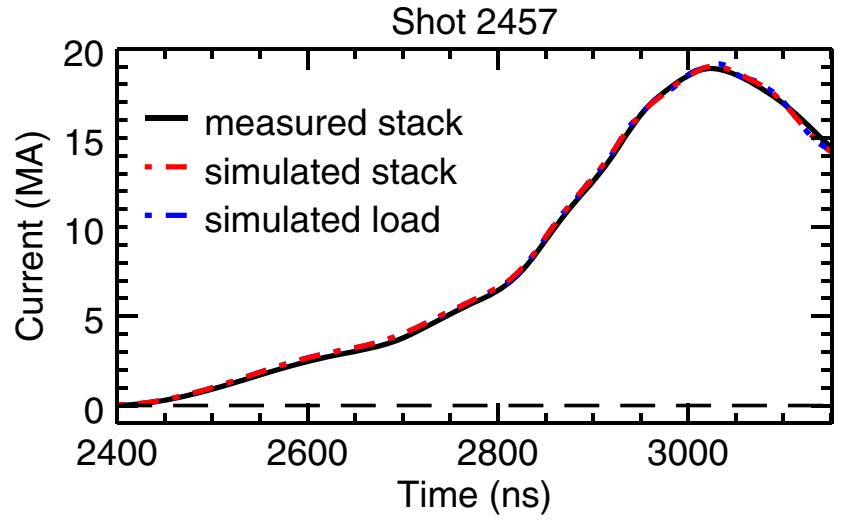

(e)

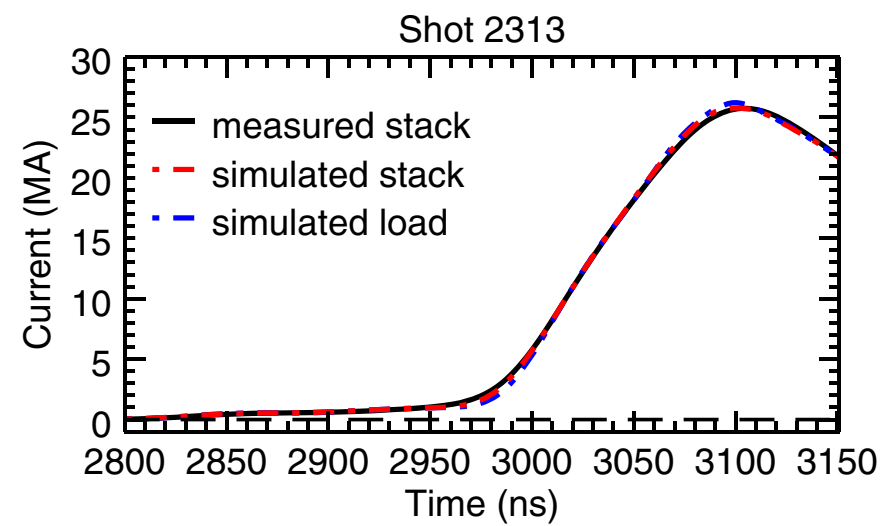

(b)

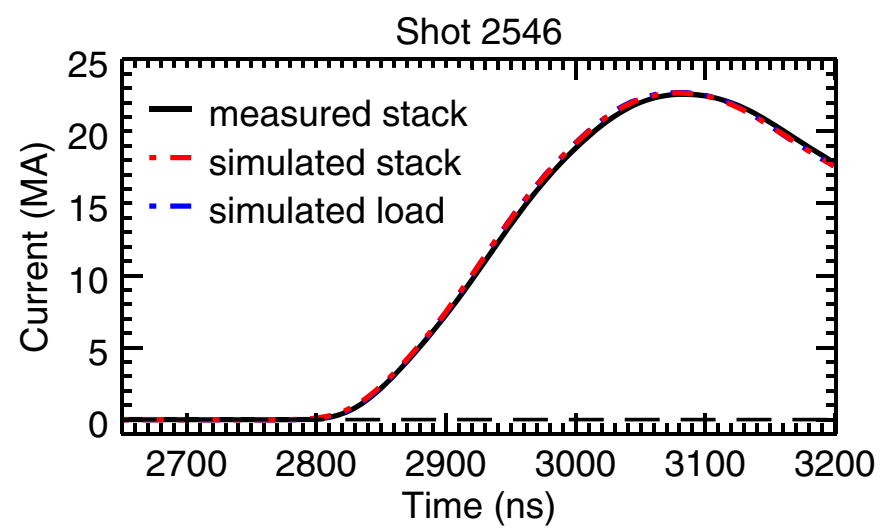

(d)

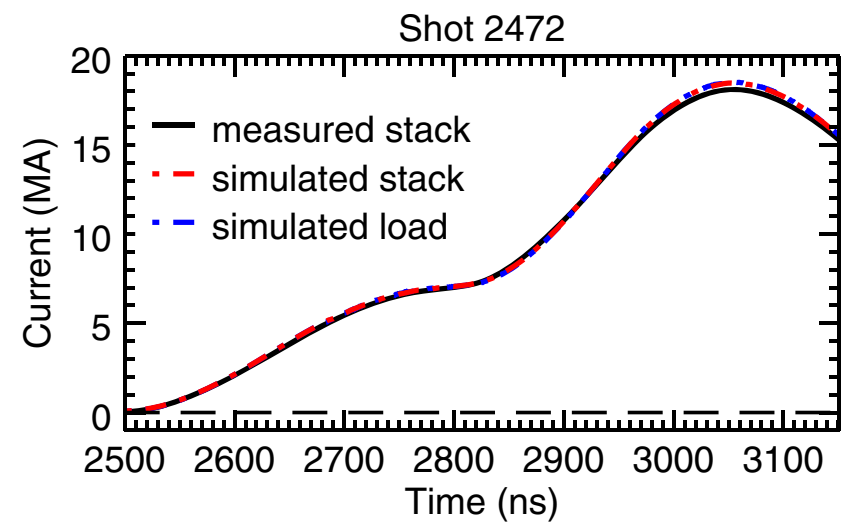

(f)

FIG. 4. Comparison of simulation and experiment results of six short-circuit shots. (a) standard pulse, (b) short pulse, (c) medium pulse, (d) long pulse, (e) shaped pulse 1, (f) shaped pulse 2.

length of the nested array is $2.0 \mathrm{~cm}$. The wire-array load was simulated using a wire-ablation model [23]. The simulated liner implosion time was assumed to be when the arrays reached a radius of $0.325 \mathrm{~cm}$ (i.e., at 10:1 convergence ratio). This convergence ratio was chosen to remain consistent with the simulations in Ref. [13], however the results are relatively insensitive to the choice of a larger convergence ratio due to the high implosion velocities of these arrays. The experimental implosion time was measured as the peak of the x-ray emission from the load measured with PCDs.

Post-shot simulations were done on eight tungsten wire-array shots. Representative comparisons of the insulator-stack time history and the load implosion time for two $\mathrm{Z}$ shots are shown in Fig. 9. The overall shape of the simulated and measured stack current agreed to within $2 \%$ for all of the simulated tungsten-wire-array shots. The simulated and measured liner implosion time 


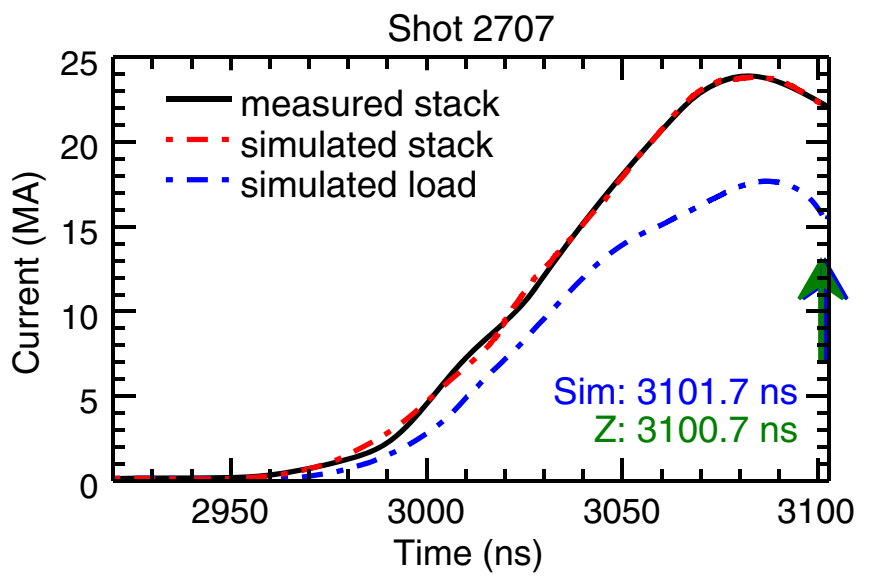

(a)

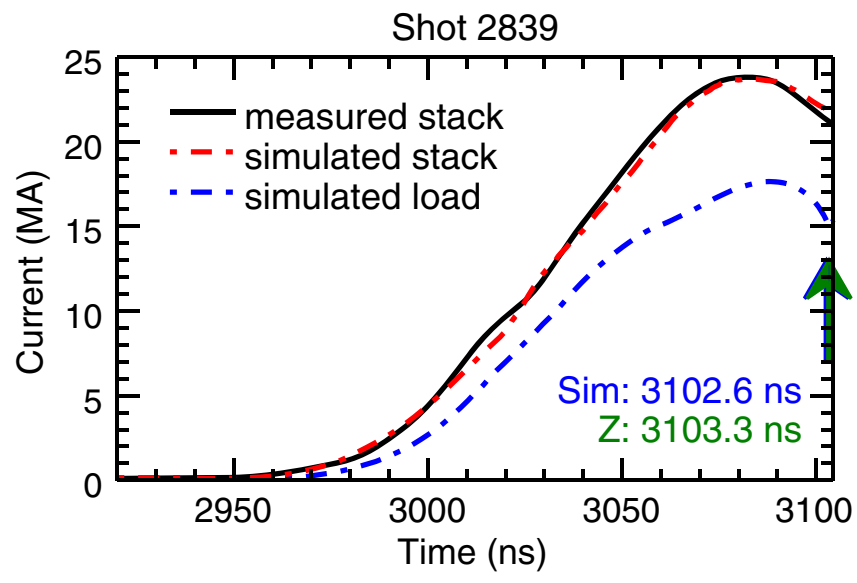

(b)

FIG. 5. Comparison of simulation and experiment results of two integrated MagLIF shots with a $10 \mathrm{~mm}$ liner [5]. (a) Z shot 2707, (b) Z shot 2839.

agreed to within $2 \mathrm{~ns}$ for all of the simulated tungsten-wirearray shots.

\section{E. Nested stainless-steel wire arrays}

The stainless-steel wire-array load consists of two components: a $3.5 \mathrm{~cm}$ initial radius, $0.5 \mathrm{mg}$ outer wire array and a $1.75 \mathrm{~cm}$ initial radius, $0.25 \mathrm{mg}$ inner array. The axial length of the nested array is $2.0 \mathrm{~cm}$. The wire-array load was simulated using a wire-ablation model [23]. The simulated liner implosion time was assumed to be when the arrays reached a radius of $0.35 \mathrm{~cm}$ (i.e., at a 10:1 convergence ratio). This convergence ratio was chosen to remain consistent with the simulations in Ref. [13], however the results are relatively insensitive to the choice of a larger convergence ratio due to the high implosion velocities of these arrays. The experimental implosion time was measured as the peak of the x-ray emission from the load measured with PCDs.

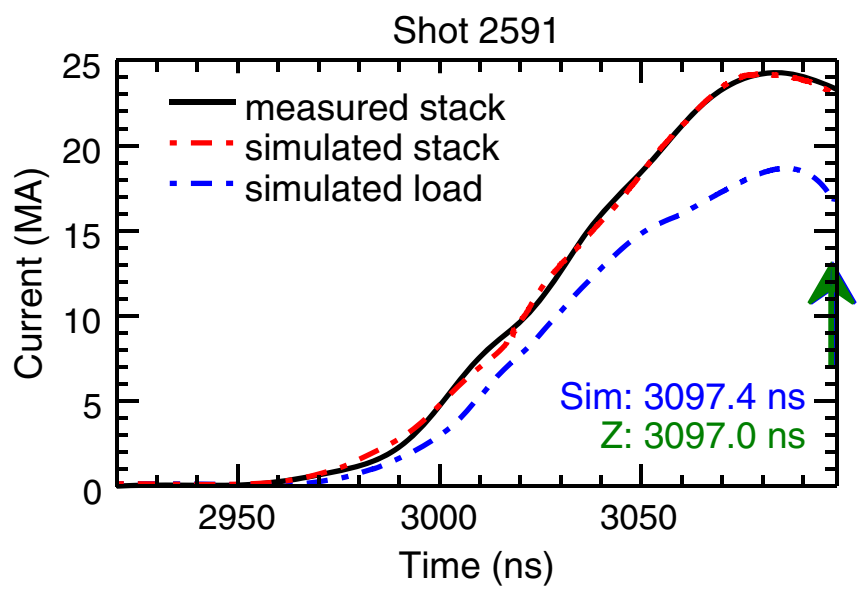

(a)

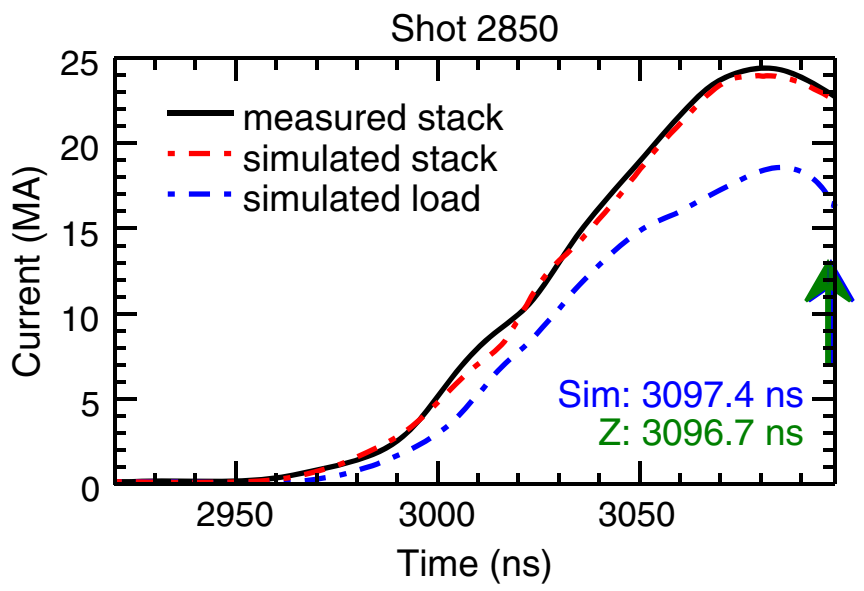

(b)

FIG. 6. Comparison of simulation and experiment results of two integrated MagLIF shots with a $7.5 \mathrm{~mm}$ liner [5]. (a) $\mathrm{Z}$ shot 2591, (b) Z shot 2850 .

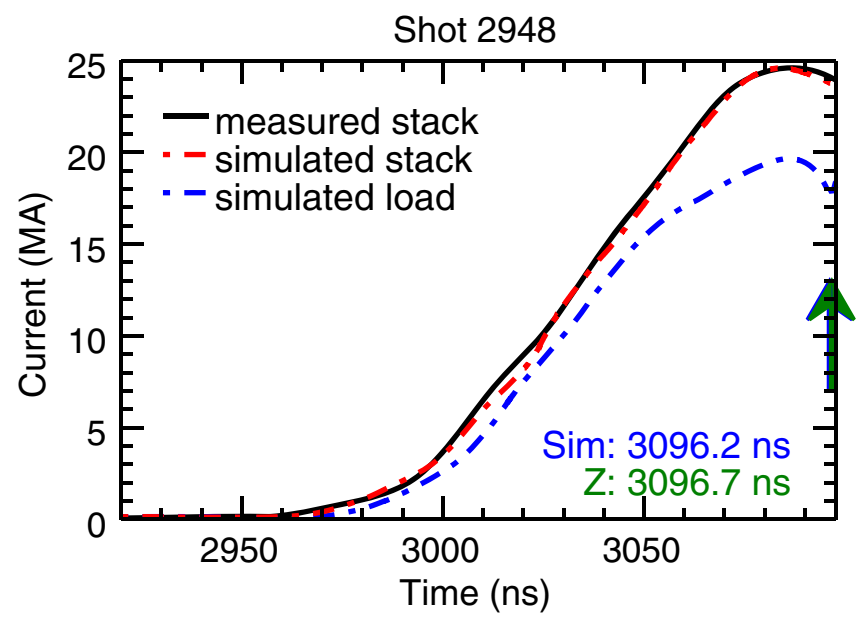

FIG. 7. Comparison of simulation and experiment results of an integrated MagLIF shot with a $7.5 \mathrm{~mm}$ liner and a low-inductance inner MITL [5]. 

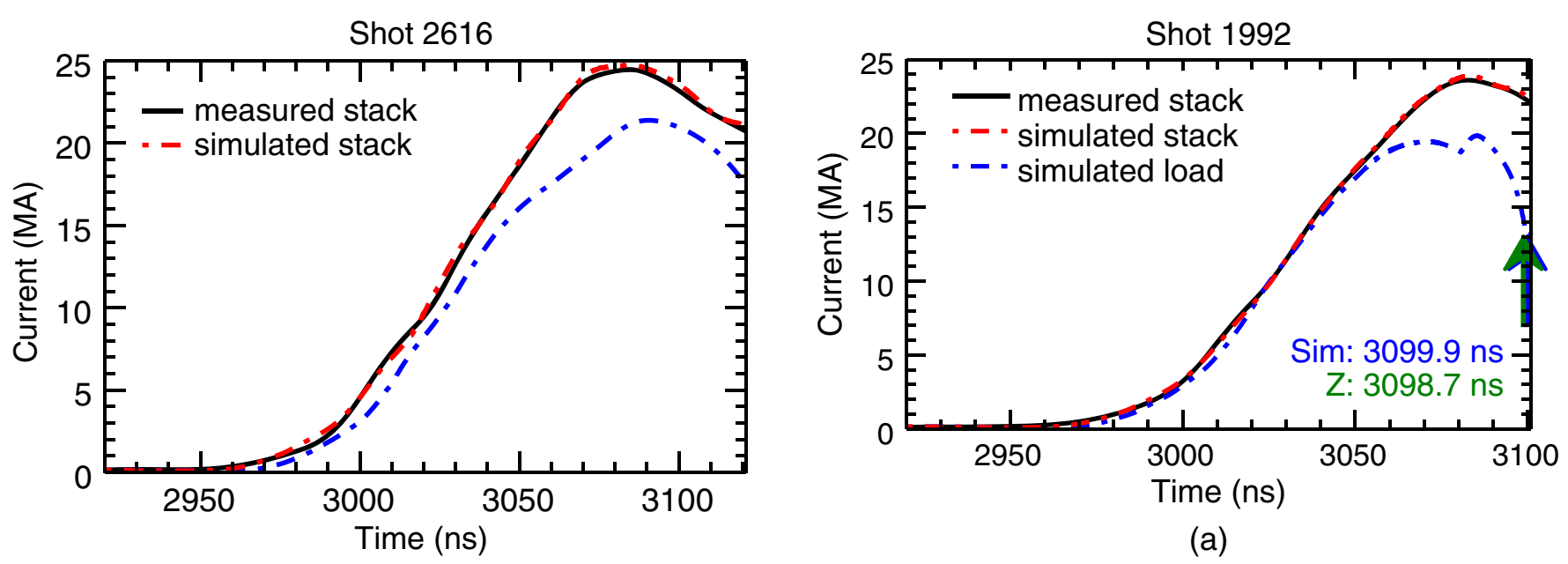

(a)
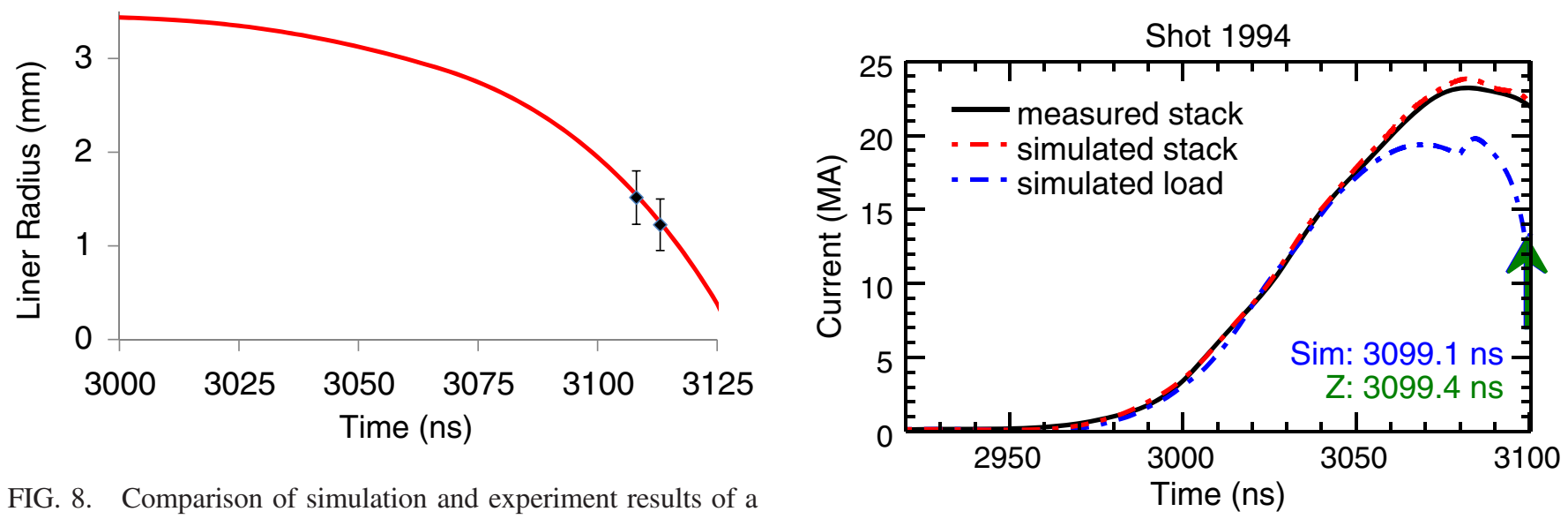

FIG. 8. Comparison of simulation and experiment results of a liner-dynamics shot. The measured insulator-stack currents agree to within $1.5 \%$. Radiographs of the imploding liner were taken at two points during the implosion. The radii of the inner and outer surface of the liner as seen in radiographs of the imploding liner are shown using the error bars. The average radius is shown using data markers. The simulated liner radius is shown in red [17-19].

Post-shot simulations were done on three stainless-steel wire-array shots. Representative comparisons of the insulator-stack time history and the load implosion time for two $\mathrm{Z}$ shots are shown in Fig. 10. The overall shape of the simulated and measured stack current agreed to within $1.6 \%$ for all of the simulated stainless-steel wire-array shots. The simulated and measured liner implosion time agreed to within $2 \mathrm{~ns}$ for all of the simulated stainless-steel wire-array shots.

\section{F. Dynamic hohlraum}

The dynamic-hohlraum load consists of three components: a $2 \mathrm{~cm}$ initial-radius, $5.66 \mathrm{mg}$ tungsten outer wire array; a $1 \mathrm{~cm}$ initial radius, $2.83 \mathrm{mg}$ tungsten inner array; and a $0.3 \mathrm{~cm}$ radius foam cylinder located on axis. The axial length of the dynamic hohlraum is $1.2 \mathrm{~cm}$. The dynamic-hohlraum load was simulated using a wireablation model [23]. To avoid the complications of

simulating the foam cylinder, in addition to the nested tungsten wire arrays, the simulated and experimental implosion times were compared assuming that the measured x-ray emission from the target begins when the wire array first strikes the foam target [38]. The simulated liner implosion time was assumed to be when the imploding mass reaches the $0.3 \mathrm{~cm}$ radius foam target. The experimental implosion time was estimated as the extrapolated beginning of the measured $\mathrm{x}$-ray emission from the target as measured with PCDs.

Post-shot simulations were done on four dynamichohlraum shots. Comparisons of the insulator-stack time history and the load implosion time are shown in Fig. 11. The overall shape of the simulated and measured stack current agreed to within $1.5 \%$ for all of the simulated dynamic-hohlraum shots. The simulated and measured liner-implosion time agreed to within $1.5 \mathrm{~ns}$ for all of the simulated dynamic hohlraum shots. 


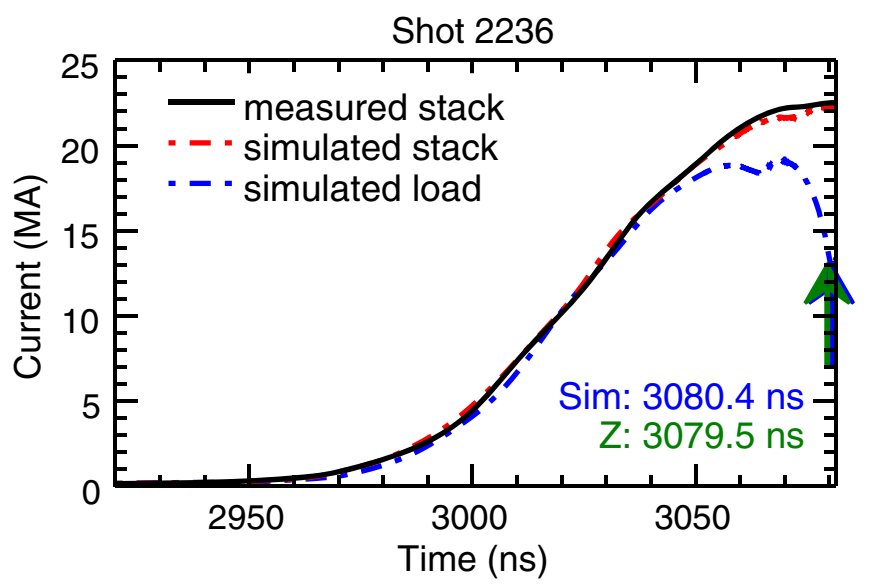

(a)

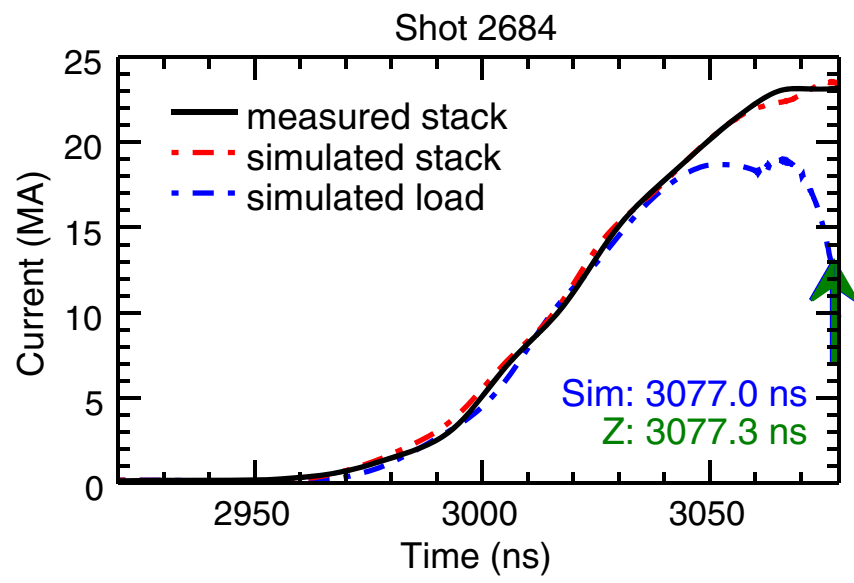

(b)

FIG. 10. Comparison of simulation and experiment results of two nested stainless-steel wire-array shots [21]. (a) Z shot 2236, (b) Z shot 2684 .

\section{CONCLUSIONS}

A transmission-line-circuit model of the $\mathrm{Z}$ accelerator has been developed to aid in the design and analysis of $Z$ experiments. The new model simulates the entire machine, including all 36 individual pulse-forming modules, from the energy storage at the Marx banks to the load.

Experiment data from several $\mathrm{Z}$ experiments were used to perform two optimizations on model parameters. The first optimization used data from eleven short-circuit shots conducted with a variety of switch configurations and Marx charge voltages to refine the gas and water switch inductances and resistances used in the circuit models of the pulse-forming modules. Typical values for these parameters were provided in Table II. The second optimization used data from six different z-pinch shots with a variety of inner MITL geometries and load-inductance time histories, resulting in varying amounts of current loss, to constrain nine parameters related to the analytic

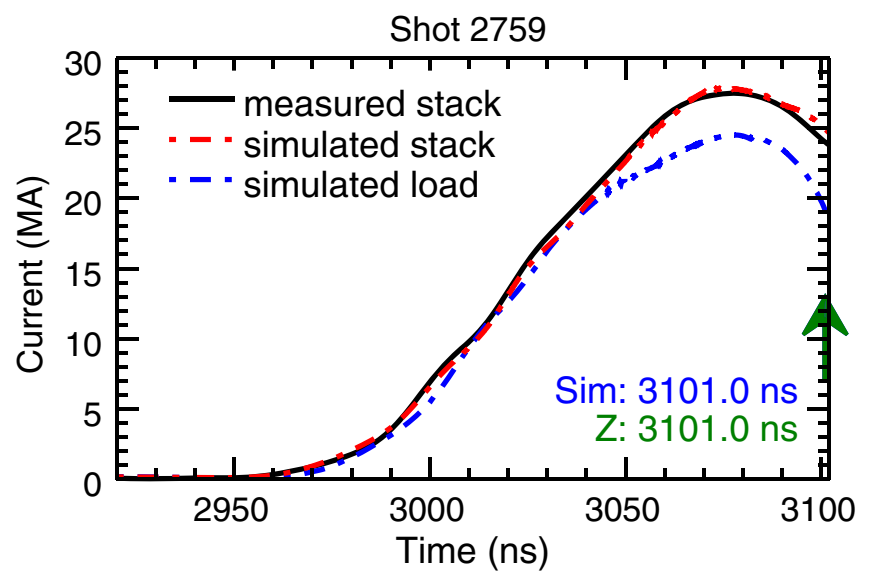

(a)

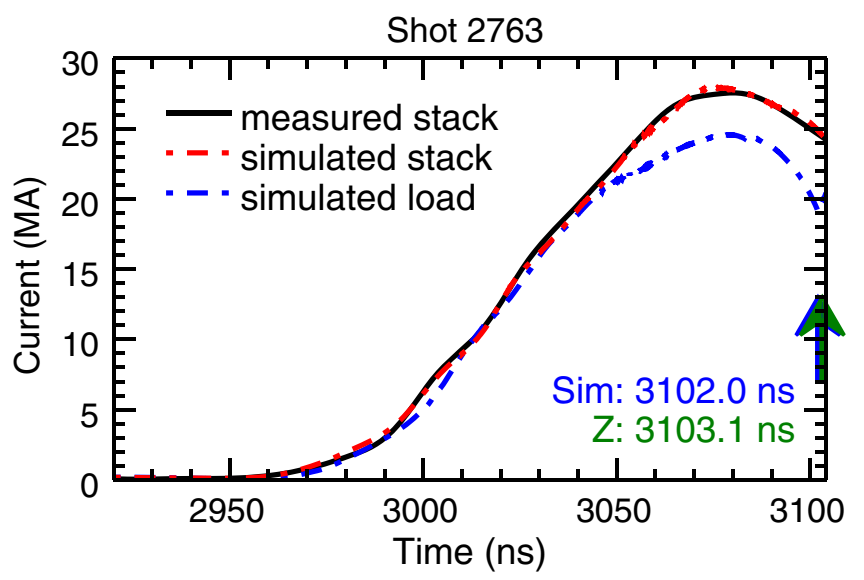

(b)

FIG. 11. Comparison of simulation and experiment results of two dynamic-hohlraum shots [11]. (a) Z shot 2759, (b) Z shot 2763.

current-loss estimates. These parameter values were provided in Table III.

The model with the empirically determined switch and current-loss parameters was then benchmarked against data from $52 \mathrm{Z}$ shots with a variety of load-impedance time histories showing good agreement with experiment data. The simulated and measured insulator stack currents agree to within $2 \%$ for all 52 shots. The simulated load-implosion times agree to within $2 \mathrm{~ns}$ for the 35 shots that were conducted with an imploding load.

Future work related to the $\mathrm{Z}$ circuit model will involve comparing the model results to additional $\mathrm{Z}$ experiments and detailed particle-in-cell simulations. Comparisons to future $\mathrm{Z}$ experiments will test the predictive capability of the model. Circuit simulations using the $\mathrm{Z}$ circuit model are being used in the design of upcoming MagLIF experiments that will use new lower-inductance inner MITL feeds and/or changes to the vacuum convolute geometry compared to the shots presented in Figs. 5-7. 
The changes are being made with the goal of reducing current loss within the vacuum convolute and inner MITL regions to deliver more current to the MagLIF target. Additionally, the model assumptions will be tested with comparisons to future $\mathrm{Z}$ experiments with additional power-flow diagnostics and 3D particle-in-cell simulations. The new diagnostics are being designed to measure conditions such as the electrode temperature, plasma density, charge species, and loss current density, within the outer MITLs, vacuum convolute, and inner MITL. The model assumptions and parameters will be updated and refined as comparisons to particle-in-cell simulations and additional experiments are conducted.

\section{ACKNOWLEDGMENTS}

The authors would like to thank Dave Ampleford, Tom Awe, Jim Bailey, Michael Jones, Patrick Knapp, Guillaume Loisel, and Michael Lopez for providing experiment details. The authors would also like to thank our colleagues at the following organizations for invaluable contributions: Sandia National Laboratories, L-3 Communications, Naval Research Laboratory, and Voss Scientific. This work was supported by the Laboratory Directed Research and Development program at Sandia National Laboratories, a multi-mission laboratory managed and operated by National Technology and Engineering Solutions of Sandia, LLC, a wholly owned subsidiary of Honeywell International, Inc., for the U.S. Department of Energy's National Nuclear Security Administration under Contract No. DE-NA0003525.

\section{APPENDIX A: OUTER MITL ELECTRON FLOW CURRENT}

The magnitude of the outer MITL electron flow current that enters the vacuum convolute and inner MITL regions is dependent on the propagation of the flow current through the outer MITLs. The outer MITLs are designed with either a constant or increasing impedance in the direction of power flow. Therefore, the magnitude of flow current [see Eq. (3)] calculated in each element decreases as the element radius decreases (in the direction of power flow), due to decreased voltage and/or increased impedance.

Outside of a radius of $20 \mathrm{~cm}$, the outer MITLs are designed with a constant impedance. It is assumed that the excess electron flow current, due to the higher voltage upstream, is effectively re-trapped at the cathode and does not propagate downstream [39]. Therefore, we do not calculate the electron flow current for elements outside of a radius of $20 \mathrm{~cm}$.

Inside a radius of $20 \mathrm{~cm}$, the outer MITLs are designed with a constant $\mathrm{AK}$ gap (i.e., increasing impedance). Additional comparisons to PIC simulations [40] suggest that the electron flow current propagating from larger radius in a constant gap, radial MITL is only effectively re-trapped at the cathode when the MITL is strongly insulated. The Bertha model was modified to include this behavior by introducing an electron flow current retrapping constant, $k_{\mathrm{rt}}$. The electron flow retrapping constant is defined as a ratio of the electron flow current to the anode current,

$$
k_{\mathrm{rt}} \equiv \frac{I_{f}}{I_{a}} .
$$

The retrapping constant used in the simulations was determined by the swarm optimization and is given in Table III.

Within a given transmission line circuit element, when the ratio of flow current to anode current is greater than $k_{\mathrm{rt}}$, it is assumed that the MITL is weakly insulated and all of the flow current from the upstream element propagates into the downstream element. This results in a flow current in the downstream element that is larger than would be given by evaluating equation (3) for that element. When the ratio is less than $k_{\mathrm{rt}}$, it is assumed that the element is strongly insulated, and a portion of the upstream flow current is retrapped. The end result is that early in time, when the flow current is weakly insulated, the magnitude of flow current that propagates into the convolute and inner MITL regions is determined by the lower impedance (larger radius) elements within the constant gap section of the outer MITLs. Late in time, when the flow current is strongly insulated, the magnitude of flow current that propagates into the convolute and inner MITL regions is determined by the higher impedance (smaller radius) elements within the constant gap section of the outer MITLs.

Equation (A2) summarizes how the flow current in a given element is calculated,

$$
I_{f, n}= \begin{cases}I_{f, n-1} & \text { if } \frac{I_{f, n}}{I_{a, n}} \geq k_{\mathrm{rt}} \\ \left(I_{f, n-1}-I_{f, n}\right) \frac{I_{f, n}}{I_{a, n}}+I_{f, n} & \text { if } \frac{I_{f, n}}{I_{a, n}}<k_{\mathrm{rt}}\end{cases}
$$

where $I_{a, n}$ is the anode current in an element, $I_{f, n}$ is the flow current in an element, and $I_{f, n-1}$ is the flow current in the upstream element.

\section{APPENDIX B: DISTRIBUTION OF OUTER MITL ELECTRON FLOW CURRENT}

The electron flow current that propagates to the end of the outer MITLs is distributed throughout the vacuum convolute and inner MITL transmission line elements. A representative circuit diagram of this region is shown in Fig. 12.

The total outer MITL flow current from all four levels is divided using four constants. The constants are defined by three parameters determined by the particle swarm optimization. The parameter values are shown in Table III. 


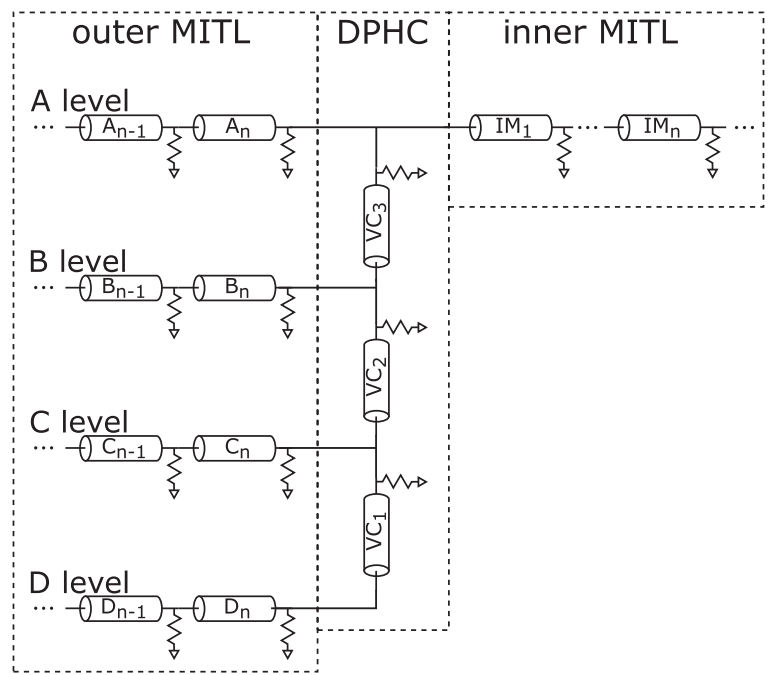

FIG. 12. Circuit diagram of the outer MITL, vacuum convolute, and inner MITL. Each transmission line element has an associated resistor to ground that is adjusted to account for current loss at each element. The electron flow current is calculated for each of the four outer MITL levels. The electron flow current that has propagated to the end of the outer MITLs is then distributed throughout the vacuum convolute (DPHC) and inner MITL regions.

$$
\begin{aligned}
& f_{\mathrm{en}, \mathrm{vc}}=e_{f, \mathrm{vc}} e_{\mathrm{en}, \mathrm{vc}}=0.040 \\
& f_{\mathrm{fl}, \mathrm{vc}}=e_{f, \mathrm{vc}}\left(1-e_{\mathrm{en}, \mathrm{vc}}\right)=0.848 \\
& f_{\mathrm{en}, \mathrm{im}}=\left(1-e_{f, \mathrm{vc}}\right) e_{\mathrm{en}, \mathrm{im}}=0.020 \\
& f_{\mathrm{fl}, \mathrm{im}}=\left(1-e_{f, \mathrm{vc}}\right)\left(1-e_{\mathrm{en}, \mathrm{im}}\right)=0.092
\end{aligned}
$$

The four equations in (B1) describe the fraction of outer MITL electron flow current that is accumulated in the vacuum convolute, $f_{\text {en,vc }}$, lost in the vacuum convolute, $f_{\text {fl } 1, \mathrm{vc}}$, accumulated in the inner MITL, $f_{\mathrm{en}, \mathrm{im}}$, and lost in the inner MITL, $f_{\mathrm{fl}, \mathrm{im}}$. The constants in (B1) are consistent with particle-in-cell simulations that show $>80 \%$ of the outer MITL electron flow current being lost to anode surfaces in the vacuum convolute [40].

Given the total incoming electron flow current from all four outer MITL levels, $I_{f}$, the total electron flow loss current or total electron flow charge accumulated in the vacuum convolute or inner MITL is given by

$$
\begin{aligned}
I_{\mathrm{fl}, \mathrm{vc}} & =f_{\mathrm{fl}, \mathrm{vc}} I_{f} \\
I_{\mathrm{fl}, \mathrm{im}} & =f_{\mathrm{fl}, \mathrm{im}} I_{f} \\
Q_{\mathrm{en}, \mathrm{vc}} & =f_{\mathrm{en}, \mathrm{vc}} \int_{0}^{t} I_{f} d t
\end{aligned}
$$

$$
Q_{\mathrm{en}, \mathrm{im}}=f_{\mathrm{en}, \mathrm{im}} \int_{0}^{t} I_{f} d t
$$

Within the convolute or inner MITL, the flow current lost or electron flow charge accumulated per element is weighted by surface area of each element. On a per element basis, the electron flow loss or accumulated electron charge is given by,

$$
\begin{aligned}
I_{\mathrm{fl} l, \mathrm{vc}, n} & =I_{\mathrm{fl}, \mathrm{vc}} \frac{A_{n}}{A_{\mathrm{vc}}} \\
I_{\mathrm{fl}, \mathrm{im}, n} & =I_{\mathrm{fl}, \mathrm{im}} \frac{A_{n}}{A_{\mathrm{im}}} \\
Q_{\mathrm{en}, \mathrm{vc}, n} & =Q_{\mathrm{en}, \mathrm{vc}} \frac{A_{n}}{A_{\mathrm{vc}}} \\
Q_{\mathrm{en}, \mathrm{im}, n} & =Q_{\mathrm{en}, \mathrm{im}} \frac{A_{n}}{A_{\mathrm{im}}},
\end{aligned}
$$

where $A_{n}$ is the surface area of the circuit element, $A_{\mathrm{vc}}$ is the total area of the vacuum convolute, and $A_{\text {im }}$ is the total area of the inner MITL.

\section{APPENDIX C: ION LOSS ENHANCEMENT}

\section{Ion current enhancement calculation}

The ion loss current is calculated assuming the transmission line regions behave as an enhanced space-chargelimited emission source, as in an applied-B ion diode [33]. In the absence of negative space charge, the SCL ion emission current is given by

$$
I_{\mathrm{SCL}}=\frac{4 \varepsilon_{0}}{9} A \sqrt{\frac{2 q}{m}} \frac{V^{3 / 2}}{d^{2}} .
$$

Negative space charge present in the AK gap from the electron flow that originates in the outer MITLs and propagates into the convolute and inner MITL can enhance the ion emission current. The enhancement, $\eta$, is defined to be the ratio of the enhanced ion loss current, $I_{\text {ion }}$, and the space-charge-limited current in the absence of negative space charge, $I_{\mathrm{SCL}}$,

$$
\eta=\frac{I_{\text {ion }}}{I_{\mathrm{SCL}}} .
$$

We can define the enhanced ion loss current and SCL current in terms of total charge in the gap, $Q$, average charge velocity, $\bar{v}$, and gap distance, $d$.

$$
I_{\mathrm{SCL}}=\frac{Q_{i_{0}} \bar{v}_{i_{0}}}{d}
$$




$$
I_{\text {ion }}=\frac{Q_{i} \bar{v}_{i}}{d}
$$

In the SCL case [41], the total ion charge and average ion velocity are given by,

$$
\begin{aligned}
Q_{i_{0}} & =\frac{4}{3} \varepsilon_{0} A \frac{V}{d} \\
\bar{v}_{i_{0}} & =\frac{1}{3} \sqrt{\frac{2 q V}{M}} .
\end{aligned}
$$

In the enhanced case we assume the total ion charge is equal to the total accumulated electron charge from the outer MITL flow current,

$$
Q_{i}=Q_{e}
$$

We assume the average ion velocity falls between two limits. In the limit of zero negative space charge, there is no enhancement and the ion diode behaves as in the SCL case. In another limit, where all the ion acceleration takes place near the anode, the average ion velocity is equal to the maximum velocity of an ion crossing a potential $\mathrm{V}$,

$$
v_{\max }=\sqrt{\frac{2 q V}{M}}=3 \bar{v}_{i_{0}} .
$$

We assume that the ion velocity in our model is bounded by these two cases,

$$
\begin{aligned}
& \bar{v}_{i_{0}} \leq \bar{v}_{i} \leq v_{\max } \\
& \bar{v}_{i_{0}} \leq \bar{v}_{i} \leq 3 \bar{v}_{i_{0}},
\end{aligned}
$$

and define a constant, $k_{\mathrm{vi}}$, which is between 1 and 3,

$$
k_{\mathrm{vi}} \equiv \frac{\bar{v}_{i}}{\bar{v}_{i_{0}}} .
$$

Combining equations, (C2)-(C7) and (C10), we can solve for the enhancement as a function of area, voltage, gap distance, electron charge, and average ion velocity,

$$
\eta=\frac{3}{4} k_{\mathrm{vi}} Q_{e} \frac{d}{\varepsilon_{0} A V} .
$$

\section{Ion current enhancement magnitude}

A bipolar ion diode has an ion-current-enhancement factor of 1.86 [42]. In such a diode, the electron-number density decreases monotonically from the cathode to the anode.

If instead, the electron-space-charge is uniformly distributed and the electron number density is constant from the cathode to the anode, the ion-current-enhancement factor is 5.55 [33]. This is a factor of 3 greater than the enhancement that is achieved when the electron density peaks at the cathode as in the nonrelativistic bipolar ion diode. The increased enhancement is to be expected since a uniform electron-density profile is more effective at canceling the ion space charge than an electron-density profile that peaks at the cathode, since the ion charge density is much higher at the anode than the cathode. When more of the ion space charge is canceled, more ion current can flow across the AK gap.

Finally, if we now consider an electron-density profile that increases monotonically from the cathode to the anode. Such an electron-density profile can be even more effective at canceling the ion space charge than an electron-density profile that is uniform across the gap. Hence, such a profile can have an ion-current-enhancement factor that is greater than 5.55.

The ion loss current enhancement in the simulations presented, as given by Eqs. (8) or (C11), were as high as 30 in the inner MITL region and as high as 10 in the vacuum convolute region. These enhancement factors are higher than a non-relativistic bipolar ion diode. We make the assumption that the $\mathrm{Z}$ vacuum convolute and inner MITL regions can operate as ion diodes with an electron-density profile that increases from the cathode to the anode permitting enhancement factors greater than 5.55. We make this assumption based on the following: (i) the electron flow current from the outer MITLs provides a large number density of electrons in the vacuum convolute and inner MITL region; (ii) the electrons within the vacuum convolute and inner MITL have a number density that is highest at the anode.

The electrons in the vacuum convolute and inner MITL regions originate from the cathodes of the $\mathrm{Z}$ accelerators four upstream outer MITLs. In a conventional bipolar ion diode, the electrons present in the diode originate from the diodes cathode electrode. The upstream MITLs have a substantially lower vacuum impedance, lower current, and higher voltage than the convolute and inner MITL. Hence, based on Eq. (3), the upstream MITLs supply substantially more electrons to the vacuum convolute and inner MITL than can be supplied by the cathodes of the vacuum convolute and inner MITL themselves.

In addition to the large magnitude of electrons, we note that the cathodes of the outer MITLs extend from a radius of $10 \mathrm{~cm}$ to $130 \mathrm{~cm}$ and the electrons emitted by these cathodes undergo collisions with electromagnetic fluctuations and electrode-plasma particles as the electrons ExB drift toward the load. As the electrons enter the vacuum convolute and inner MITL we expect them to have a wide range of canonical momenta and energies. Consequently, we expect such electrons to be present throughout the AK gaps of the vacuum convolute and inner MITL. Furthermore, as the outer-MITL electrons ExB drift toward the load, they also drift toward the anode providing a electron number density that is highest at the anodes [43]. 
[1] M. E. Savage et al., An overview of pulse compression and power flow in the upgraded $\mathrm{Z}$ pulsed power driver, in Proceedings of the 16th IEEE International Pulsed Power Conference (IEEE, Albuquerque, NM, 2007), p. 979, DOI: 10.1109/PPPS.2007.4652354.

[2] M. E. Savage, K. R. LeChien, M. R. Lopez, B. S. Stoltzfus, W. A. Stygar, D. S. Artery, J. A. Lott, and P. A. Corcoran, Status of the $\mathrm{Z}$ pulsed power driver, in IEEE Pulsed Power Conference, Chicago, IL, 2011 (IEEE, Chicago, IL, 2011), p. 983, DOI: 10.1109/PPC.2011.6191629.

[3] S. A. Slutz, M. C. Herrmann, R. A. Vesey, A. B. Sefkow, D. B. Sinars, D. C. Rovang, K. J. Peterson, and M. E. Cuneo, Pulsed-power-driven cylindrical liner implosions of laser preheated fuel magnetized with an axial field, Phys. Plasmas 17, 056303 (2010).

[4] M. E. Cuneo et al., Magnetically driven implosions for inertial confinement fusion at sandia national laboratories, IEEE Trans. Plasma Sci. 40, 3222 (2012).

[5] M. R. Gomez et al., Experimental Demonstration of Fusion-Relevant Conditions in Magnetized Liner Inertial Fusion, Phys. Rev. Lett. 113, 155003 (2014).

[6] B. Jones, C. A. Coverdale, C. Deeney, D. B. Sinars, E. M. Waisman, M. E. Cuneo, D. J. Ampleford, P. D. LePell, K. R. Cochrane, J. W. Thornhill, J. P. Apruzese, A. Dasgupta, K. G. Whitney, R. W. Clark, and J. P. Chittenden, Implosion dynamics and $\mathrm{K}$-shell $\mathrm{x}$-ray generation in large diameter stainless steel wire array $\mathrm{Z}$ pinches with various nesting configurations, Phys. Plasmas 15, 122703 (2008).

[7] B. Jones et al., The effect of gradients at stagnation on K-shell x-ray line emission in high-current Ar gas-puff implosions, Phys. Plasmas 22, 020706 (2015).

[8] M. R. Martin, R. W. Lemke, R. D. McBride, J. P. Davis, D. H. Dolan, M. D. Knudson, K. R. Cochrane, D. B. Sinars, I. C. Smith, M. Savage, W. A. Stygar, K. Killebrew, D. G. Flicker, and M. C. Herrmann, Solid liner implosions on $\mathrm{Z}$ for producing multi-megabar, shockless compressions, Phys. Plasmas 19, 056310 (2012).

[9] R. W. Lemke, D. H. Dolan, D. G. Dalton, J. L. Brown, K. Tomlinson, G. R. Robertson, M. D. Knudson, E. Harding, A. E. Mattsson, J. H. Carpenter, R. R. Drake, K. Cochrane, B. E. Blue, A. C. Robinson, and T. R. Mattsson, Probing off-Hugoniot states in $\mathrm{Ta}, \mathrm{Cu}$, and $\mathrm{Al}$ to $1000 \mathrm{GPa}$ compression with magnetically driven liner implosions, J. Appl. Phys. 119, 015904 (2016).

[10] J. E. Bailey, G. A. Chandler, D. Cohen, M. E. Cuneo, M. E. Foord, R. F. Heeter, D. Jobe, P. W. Lake, J. J. MacFarlane, T. J. Nash, D. S. Nielson, R. Smelser, and J. Torres, Radiation science using Z-pinch x rays, Phys. Plasmas 9, 2186 (2002).

[11] G. A. Rochau, J. E. Bailey, R. E. Falcon, G. P. Loisel, T. Nagayama, R. C. Mancini, I. Hall, D. E. Winget, M. H. Montgomery, and D. A. Liedahl, ZAPP: The Z Astrophysical Plasma Properties collaboration, Phys. Plasmas 21, 056308 (2014).

[12] D. D. Hinshelwood, Naval Research Laboratory Memorandum Report No. 5185, 1983.

[13] W. A. Stygar et al., 55-TW magnetically insulated transmission-line system: Design, simulations, and performance, Phys. Rev. ST Accel. Beams 12, 120401 (2009).
[14] P. A. Corcoran, B. A. Whitney, V. L. Bailey, I. D. Smith, W. A. Stygar, M. E. Savage, G. A. Rochau, J. E. Bailey, B. M. Jones, T. J. Nash, M. E. Sceiford, L. G. Schlitt, and J. W. Douglas, Circuit modeling techniques applied to ZR, in IEEE Pulsed Power Conference, Washington, DC, 2009 (IEEE, Washington, DC, 2009), p. 150.

[15] M. A. Kemp, S. D. Kovaleski, B. T. Hutsel, A. Benwell, and J. M. Gahl, Particle swarm optimization of pulsed power circuit models, IEEE Trans. Plasma Sci. 36, 2722 (2008).

[16] B. T. Hutsel et al., in 19th IEEE International Pulsed Power Conference (IEEE, Piscataway, NJ, 2013).

[17] R. D. McBride et al., Beryllium liner implosion experiments on the $\mathrm{Z}$ accelerator in preparation for magnetized liner inertial fusion, Phys. Plasmas 20, 056309 (2013).

[18] R. D. McBride et al., Penetrating Radiography of Imploding and Stagnating Beryllium Liners on the Z Accelerator, Phys. Rev. Lett. 109, 135004 (2012).

[19] D. B. Sinars et al., Measurements of Magneto-RayleighTaylor Instability Growth during the Implosion of Initially Solid Al Tubes Driven by the 20-MA, 100-ns Z Facility, Phys. Rev. Lett. 105, 185001 (2010).

[20] M. C. Jones, D. J. Ampleford, M. E. Cuneo, R. Hohlfelder, C. A. Jennings, D. W. Johnson, B. Jones, M. R. Lopez, J. MacArthur, J. A. Mills, T. Preston, G. A. Rochau, M. Savage, D. Spencer, D. B. Sinars, and J. L. Porter, X-ray power and yield measurements at the refurbished $\mathrm{Z}$ machine, Rev. Sci. Instrum. 85, 083501 (2014).

[21] D. J. Ampleford, C. A. Jennings, B. Jones, S. B. Hansen, M. E. Cuneo, C. A. Coverdale, M. C. Jones, T. M. Flanagan, M. Savage, W. A. Stygar, M. R. Lopez, J. P. Apruzese, J. W. Thornhill, J. L. Giuliani, and Y. Maron, K-shell emission trends from 60 to $130 \mathrm{~cm} / \mu$ s stainless steel implosions, Phys. Plasmas 20, 103116 (2013).

[22] D. V. Rose, D. R. Welch, E. A. Madrid, C. L. Miller, R. E. Clark, W. A. Stygar, M. E. Savage, G. A. Rochau, J. E. Bailey, T. J. Nash, M. E. Sceiford, K. W. Struve, P. A. Corcoran, and B. A. Whitney, Three-dimensional electromagnetic model of the pulsed-power Z-pinch accelerator, Phys. Rev. ST Accel. Beams 13, 010402 (2010).

[23] S. V. Lebedev, F. N. Beg, S. N. Bland, J. P. Chittenden, A. E. Dangor, M. G. Haines, K. H. Kwek, S. A. Pikuz, and T. A. Shelkovenko, Effect of discrete wires on the implosion dynamics of wire array $\mathrm{Z}$ pinches, Phys. Plasmas $\mathbf{8}$, 3734 (2001).

[24] M. S. Di Capua and D. G. Pellinen, Propagation of power pulses in magnetically insulated vacuum transmission lines, J. Appl. Phys. 50, 3713 (1979).

[25] R. B. Spielman and Y. Gryazin, Screamer: A optimized pulsed-power circuit-analysis tool, in IEEE International Power Modulator and High Voltage Conference (IPMHVC), San Francisco, CA (2016), pp. 269-274, DOI: 10.1109/IPMHVC.2016.8012884.

[26] J. P. VanDevender, T. D. Pointon, D. B. Seidel, K. W. Struve, C. Jennings, B. V. Oliver, and L. X. Schneider, Requirements for self-magnetically insulated transmission lines, Phys. Rev. ST Accel. Beams 18, 030401 (2015).

[27] W. Zou, F. Guo, L. Chen, S. Song, M. Wang, W. Xie, and J. Deng, Full circuit calculation for electromagnetic pulse 
transmission in a high current facility, Phys. Rev. ST Accel. Beams 17, 110401 (2014).

[28] W. A. Stygar, T. C. Wagoner, H. C. Ives, P. A. Corcoran, M. E. Cuneo, J. W. Douglas, T. L. Gilliland, M. G. Mazarakis, J. J. Ramirez, J. F. Seamen, D. B. Seidel, and R. B. Spielman, Analytic model of a magnetically insulated transmission line with collisional flow electrons, Phys. Rev. ST Accel. Beams 9, 090401 (2006).

[29] B. T. Hutsel, B. S. Stoltzfus, E. W. Breden, W. E. Fowler, P. A. Jones, D. W. Justus, F. W. Long, D. J. Lucero, K. A. MacRunnels, M. G. Mazarakis, J.L. McKenney, J. K. Moore, T. D. Mulville, J. L. Porter, M. E. Savage, and W. A. Stygar, Millimeter-gap magnetically insulated transmission line power flow experiments, in IEEE Pulsed Power Conference (PPC), Austin, TX (IEEE, Austin, TX, 2015), pp. 1-5, DOI: 10.1109/PPC.2015.7296902.

[30] W. A. Stygar et al., Energy loss to conductors operated at lineal current densities $\leq 10 \mathrm{MA} / \mathrm{cm}$ : Semianalytic model, magnetohydrodynamic simulations, and experiment, Phys. Rev. ST Accel. Beams 11, 120401 (2008).

[31] M.E. Cuneo, The effect of electrode contamination, cleaning and conditioning on high-energy pulsed-power device performance, IEEE Transactions on Dielectrics and Electrical Insulation 6, 469 (1999).

[32] T. W. L. Sanford, J. A. Halbleib, J. W. Poukey, A. L. Pregenzer, R. C. Pate, C. E. Heath, R. Mock, G. A. Mastin, D. C. Ghiglia, T. J. Roemer, P. W. Spence, and G. A. Proulx, Measurement of electron energy deposition necessary to form an anode plasma in $\mathrm{Ta}, \mathrm{Ti}$, and $\mathrm{C}$ for coaxial bremsstrahlung diodes, J. Appl. Phys. 66, 10 (1989).

[33] M. P. Desjarlais, Theory of applied-B ion diodes, Phys. Fluids B 1, 1709 (1989).

[34] A. W. Hull, The effect of a uniform magnetic field on the motion of electrons between coaxial cylinders, Phys. Rev. 18, 31 (1921).

[35] M. J. Berger, J. S. Coursey, M. A. Zucker, and J. Chang, ESTAR, PSTAR, and ASTAR: Computer Programs for
Calculating Stopping-Power and Range Tables for Electrons, Protons, and Helium Ions (version 1.2.3). [Online] Available: http://physics.nist.gov/Star [2018, March 5]. National Institute of Standards and Technology, Gaithersburg, MD.

[36] M. R. Gomez, R. M. Gilgenbach, M. E. Cuneo, C. A. Jennings, R. D. McBride, E. M. Waisman, B. T. Hutsel, W. A. Stygar, D. V. Rose, and Y. Maron, Experimental study of current loss and plasma formation in the $\mathrm{Z}$ machine post-hole convolute, Phys. Rev. Accel. Beams 20, 010401 (2017).

[37] R. D. McBride and S. A. Slutz, A semi-analytic model of magnetized liner inertial fusion, Phys. Plasmas 22, 052708 (2015).

[38] T. W. L. Sanford, R. W. Lemke, R. C. Mock, G. A. Chandler, R. J. Leeper, C. L. Ruiz, D. L. Peterson, R. E. Chrien, G. C. Idzorek, R. G. Watt, and J.P. Chittenden, Dynamics and characteristics of a 215-eV dynamic-hohlraum X-ray source on Z, Phys. Plasmas 9, 3573 (2002).

[39] T. D. Pointon and M. E. Savage, 2-D PIC Simulations of Electron Flow in the Magnetically Insulated Transmission Lines of Z and ZR, in 2005 IEEE Pulsed Power Conference, Monterey, CA (2005), p. 151, DOI: 10.1109/PPC.2005.300529.

[40] D. Rose (private communication).

[41] R. J. Umstattd, C. G. Carr, C. L. Frenzen, J. W. Luginsland, and Y. Y. Lau, A simple physical derivation of ChildLangmuir space-charge-limited emission using vacuum capacitance, Am. J. Phys. 73, 160 (2005).

[42] S. Humphries, Charged Particle Beams (Dover Publications, New York, 1990), p. 241.

[43] E. A. Madrid, D. V. Rose, D. R. Welch, R. E. Clark, C. B. Mostrom, W. A. Stygar, M. E. Cuneo, M. R. Gomez, T. P. Hughes, T. D. Pointon, and D. B. Seidel, Steady-state modeling of current loss in a post-hole convolute driven by high power magnetically insulated transmission lines, Phys. Rev. ST Accel. Beams 16, 120401 (2013). 